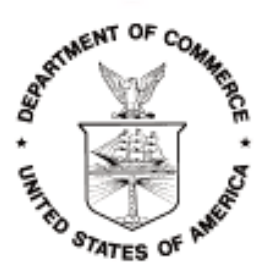

\title{
NIT
}

National Institute of

Standards and Technology

U.S. Department of Commerce

\section{Examination of Grain Moisture Meters Using Air-Oven Reference Method Transfer Standards}

PART 1: Laboratory Grain Sample Preparation and Testing PART 2: Field Inspection and Evaluation

This publication is available free of charge from: http://dx.doi.org/10.6028/NIST.HB.159

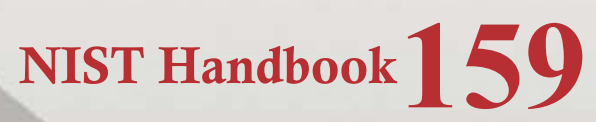

2016 
INSIDE FRONT COVER - BLANK 


\title{
Examination of Grain Moisture Meters Using Air-Oven Reference Method Transfer Standards
}

\section{Part 1: Laboratory Grain Sample Preparation and Testing Part 2: Field Inspection and Evaluation}

\author{
G. Diane Lee, Physical Scientist \\ Georgia Harris, Acting Chief \\ Office of Weights and Measures \\ Physical Measurement Laboratory
}

This publication is available free of charge from:

http://dx.doi.org/10.6028/NIST.HB.159

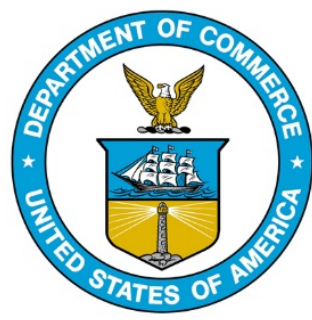

July 2016

U. S. Department of Commerce Penny Pritzker, Secretary

National Institute of Standards and Technology Willie E. May, Under Secretary of Commerce for Standards and Technology and Director

$\begin{array}{rr}\text { NIST } & 159\end{array}$


Certain commercial entities, equipment, or materials may be identified in this document in order to describe an experimental procedure or concept adequately. Such identification is not intended to imply recommendation or endorsement by the National Institute of Standards and Technology, nor is it intended to imply that the entities, materials, or equipment are necessarily the best available for the purpose.

National Institute of Standards and Technology Handbook 159, 2016 Edition Natl. Inst. Stand. Technol. Handb. 159, 2016 Ed., 78 pages (July 2016) 


\section{Preface}

State and local weights and measures jurisdictions or other testing laboratories that use transfer standards developed using the air-oven reference methods (referred to as "air-oven reference standards) to test commercial grain moisture meters collect grains that are typically grown and traded in their State and transport them to their laboratory for testing. In the laboratory, these grains are cleaned, mixed, and tested to determine moisture content and test weight. The grains are then divided into smaller grain samples and assigned moisture and test weight reference values.

These samples with known reference moisture and weight per bushel values are issued to weights and measures officials to test commercial grain moisture meters in accordance with NIST Handbook 44, Specifications, Tolerances, and Other Technical Requirements for Weighing and Measuring Devices, Section 5.56.(a) "Grain Moisture Meters.” Commercial grain moisture meters are meters that provide rapid measurement of grain moisture content during the sale of a quantity of grain. The moisture content of grain is used to determine the amount of money a seller will receive for the grain. For example, if grain moisture content is too high, the buyer must dry the grain before storage, so cost adjustments are made by the buyer to offset the cost for drying. Conversely, if the moisture is too low the grain quality may be affected and cost adjustments may be made for low moisture.

This reference manual provides technical guidelines for: (1) laboratory grain sample preparation and testing; and (2) the field evaluation of grain moisture meters and multi-constituent grain analyzers that measure moisture in accordance with NIST Handbook 44, Section 5.56.(a) for field testing using air-oven reference method transfer standards.

This manual is one of a number of manuals published by the National Institute of Standards and Technology that are designed to present, in compact form, comprehensive technical guidance for state and local weights and measures officials. Individual reference manuals for the various types of measuring devices in NIST Handbook 44 are being considered in acknowledgement of the rapidly developing technological character of commercial measurement and the ever-changing equipment used in the measurement process.

Although this handbook is prepared primarily for use by State and local weights and measures officials, the information may also be useful to manufacturers and commercial and industrial establishments interested in evaluating grain moisture meters. 


\section{Acknowledgements}

Special thanks go to the following individuals and groups for their technical contributions, reviews, and input in the preparation of this handbook:

National Type Evaluation Technical Committee (NTETC), Grain Analyzer Sector EPO Work Group:

John W. Barber, JB Associates

Cathleen Brenner, USDA, GIPSA

Randy Burns, Arkansas

Sid Colbrook, Illinois (Illinois Weights and Measures, Retired)

Bob Davis, Illinois

John Fecht, Nebraska

Richard Pierce, (USDA, GIPSA, Retired)

Fred Seeber, Shore Sales Company, Inc.

Cheryl Tew, (North Carolina Weights and Measures, Retired)

Bob Wittenberger, (Missouri Weights and Measures, Retired)

Will Wotthlie, (Maryland Weights and Measures, Retired)

NIST Office of Weights and Measures Staff:

Tina Butcher

Linda Crown

\section{References}

T. Butcher, L. Crown, R. Harshman, J. Williams, NIST Handbook 44 - Specifications and Tolerances and other Technical Requirements for Weighing and Measuring Devices, latest edition.

USDA, GIPSA, Technical Services Division, Air-Oven Moisture Reference Laboratory Working Instructions, latest edition.

USDA GIPSA, Moisture Handbook, January 1999.

USDA, GIPSA, Equipment Handbook, October 1996.

J. W. Barber, JB Associates, Grain Moisture Meters from Theory to Practice (slide presentation), 2001. 


\section{Acronyms}

CC NTEP Certificate of Conformance

EPO Examination Procedure Outline

GA Grain Analyzer

GIPSA ..Grain Inspection Packers and Stockyards Administration GMM Grain Moisture Meter

Handbook 44 NIST Handbook 44, Specifications, Tolerances, and Other Technical Requirements for Weighing and Measuring Devices

NCWM. National Conference on Weights and Measures, Inc. NIST. National Institute of Standards and Technology NTEP National Type Evaluation Program

OWM Office of Weights and Measures

USDA. U.S. Department of Agriculture USNWG U.S. National Work Group 
This page intentionally left blank 


\section{TABLE OF CONTENTS}

PREFACE iii

PART 1: LABORATORY GRAIN SAMPLE PREPARATION AND TESTING................. 1

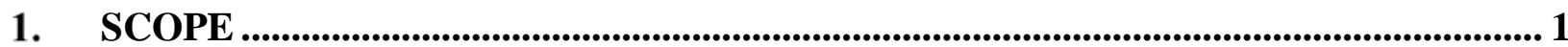

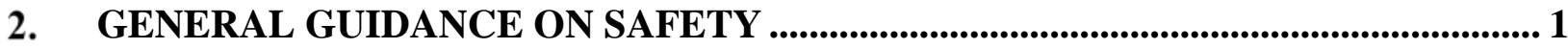

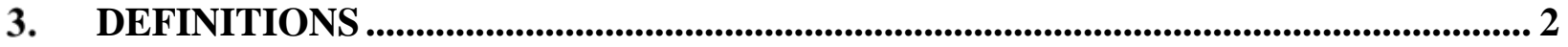

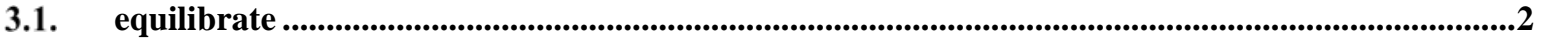

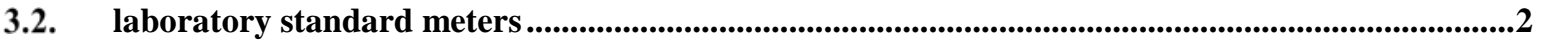

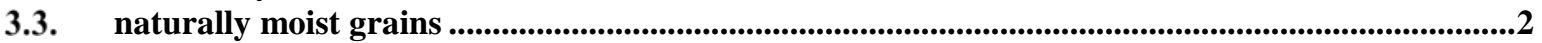

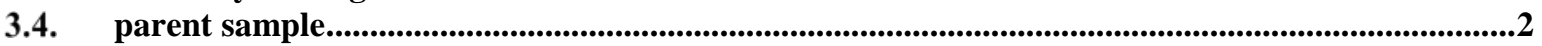

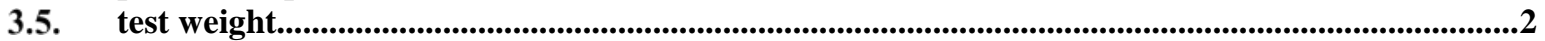

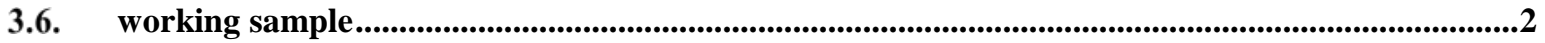

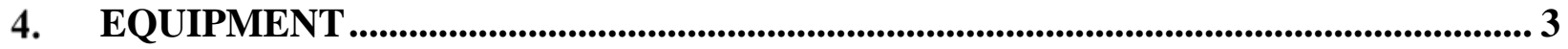

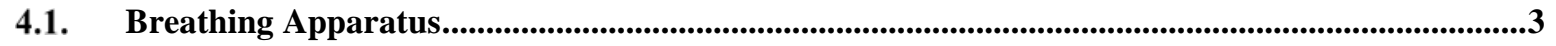

4.2. Grain Sample Cleaning and Mixing Equipment ................................................................................

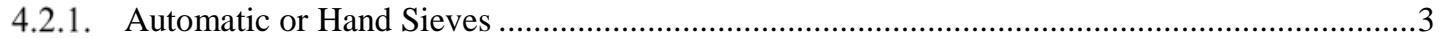

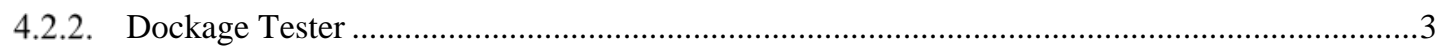

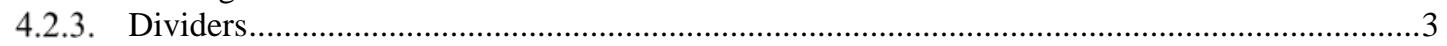

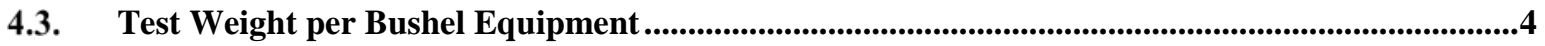

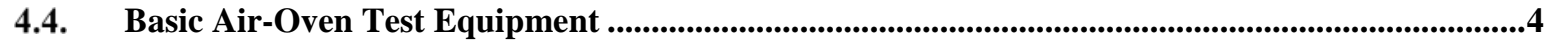

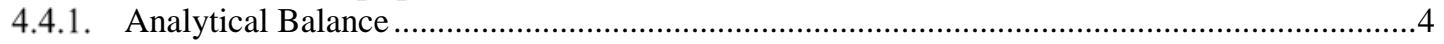

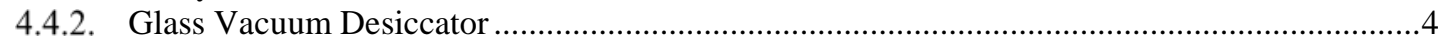

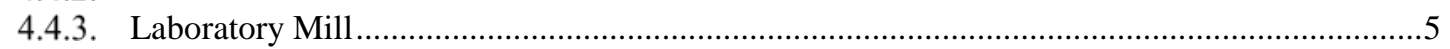

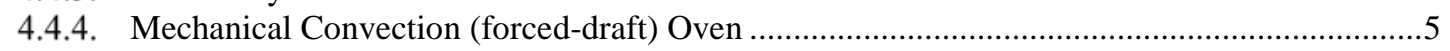

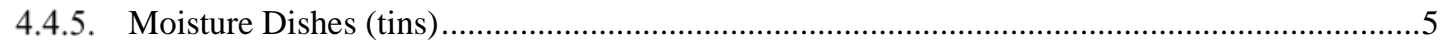

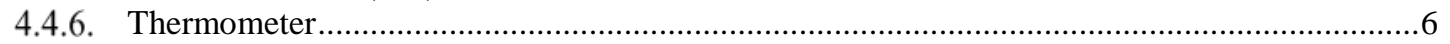

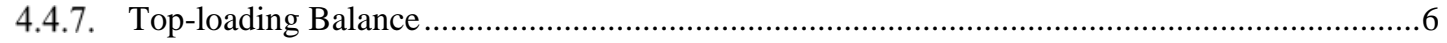

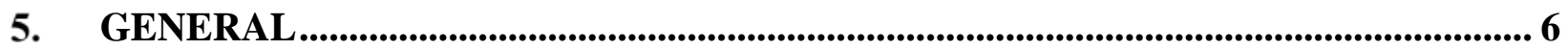

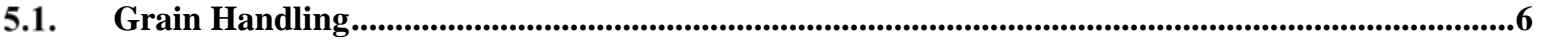

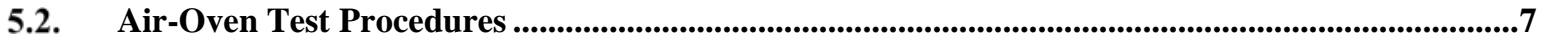

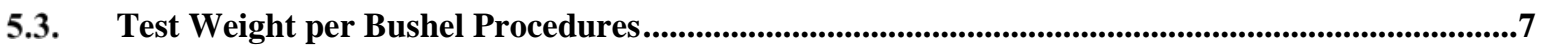

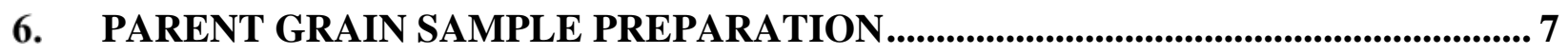

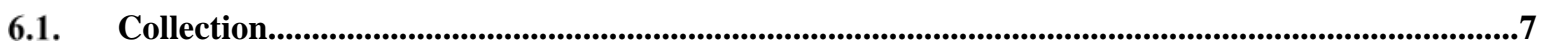




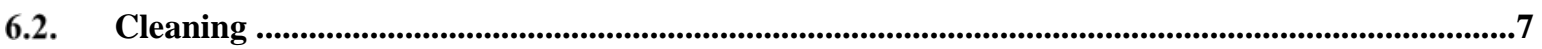

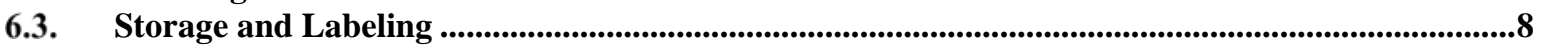

7. WORKING SAMPLE PREPARATION ...................................................................... 8

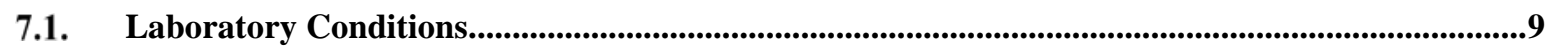

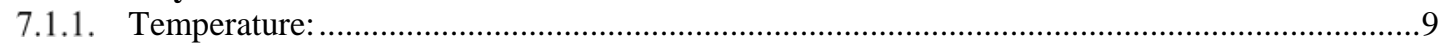

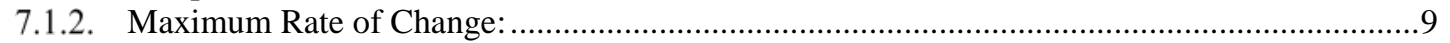

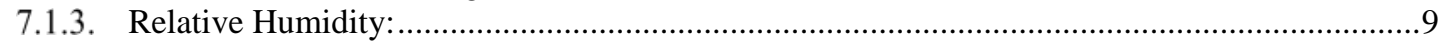

7.2. Preparing Working Samples for Testing............................................................................................9

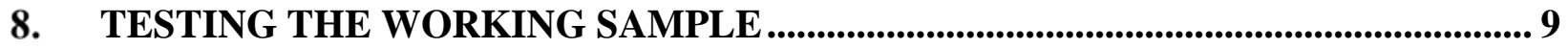

8.1. Laboratory Standard Meter Moisture Measurements.......................................................................9

8.2. Reference Air-Oven Moisture Measurements ...........................................................................9

8.3. Laboratory Standard Meter Moisture vs. Reference Air-Oven Moisture Bias ................................10

8.4. Requirement for Laboratory Standard Meter Moisture vs. Reference Air-Oven Moisture Bias

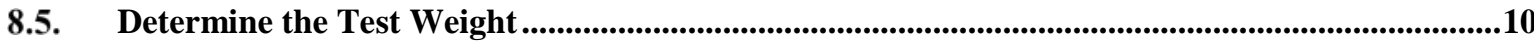

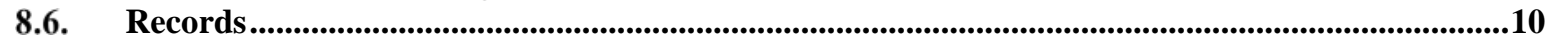

8.6.1. Parent and Working Samples .............................................................................................. 10

8.6.2. Field Samples......................................................................................................................11

9. SELECTING AND PREPARING OFFICIAL GRAIN SAMPLES ............................. 11

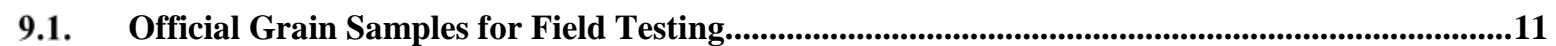

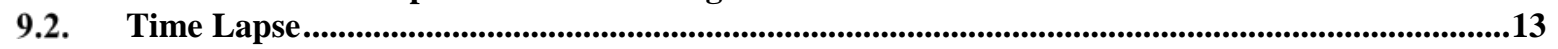

10. RETESTING AND REUSING OFFICIAL GRAIN SAMPLES .............................. 13

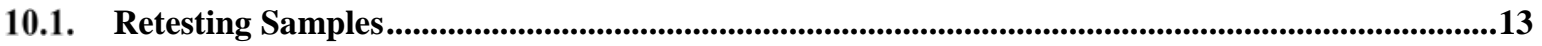

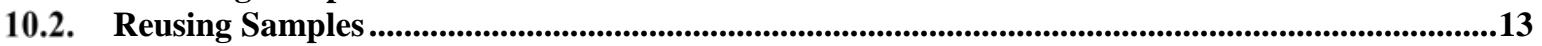

PART 2: FIELD INSPECTION AND EVALUATION

EPO NO. XX

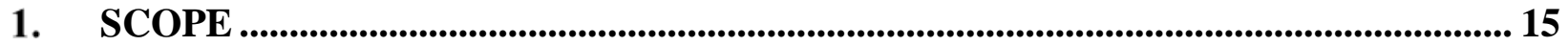

2. GENERAL GUIDANCE ON SAFETY ............................................................................... 15

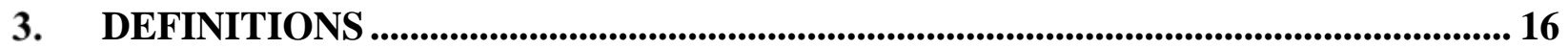

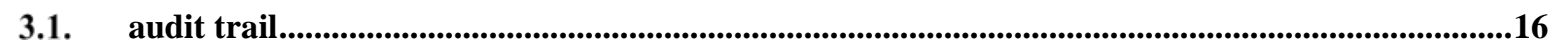

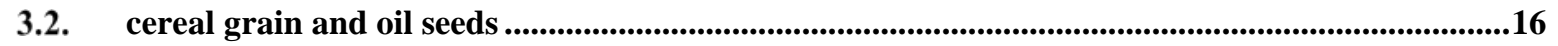

3.3. constituent ..............................................................................................................................................16

3.4. back-up sample.....................................................................................................................16

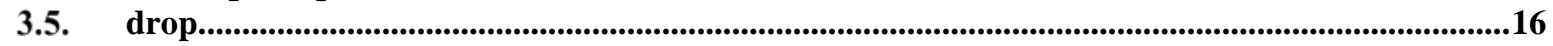

3.6. grain calibration ...................................................................................................................................17

3.7. grain moisture meter................................................................................................................17

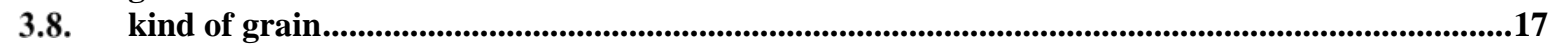

3.9. moisture content (wet basis) .....................................................................................................................17

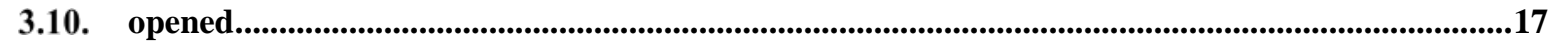

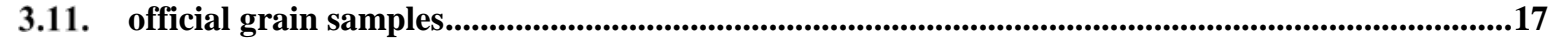




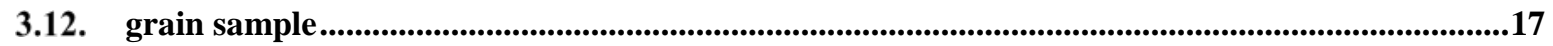

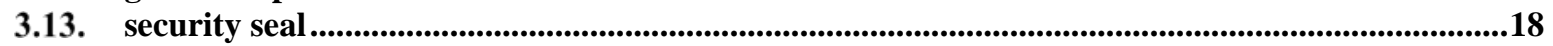

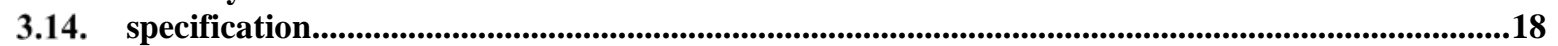

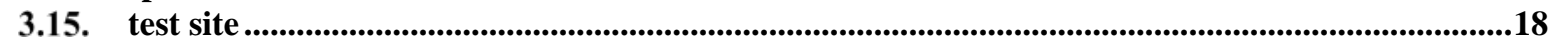

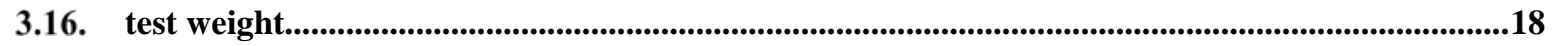

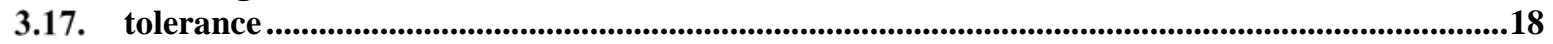

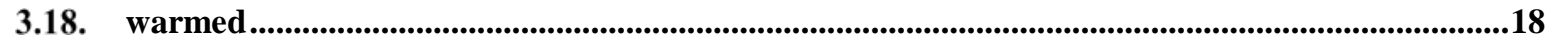

4. FIELD EQUIPMENT AND GRAIN SAMPLES............................................................... 18

4.1. Apparatus and Equipment ...........................................................................................................19

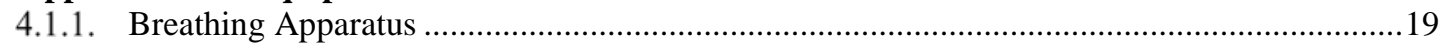

4.1.2. Thermometer...………………………………………………………………………....

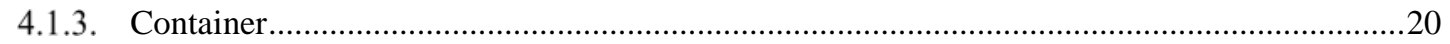

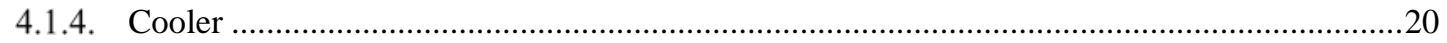

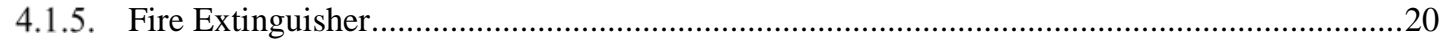

4.1.6. First Aid Kit ....……………………………………………………………………………2

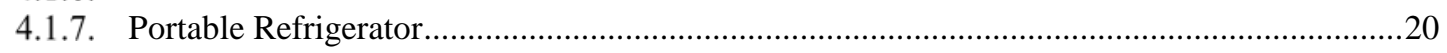

4.1.8. Grain Sample Racks..........................................................................................................21

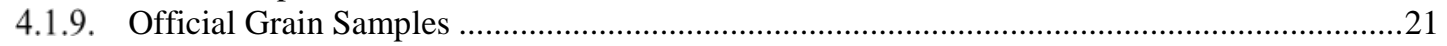

4.1.10. Personal Protection Equipment (PPE) …………………………………………………...22

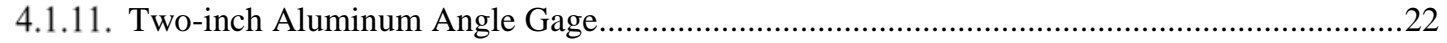

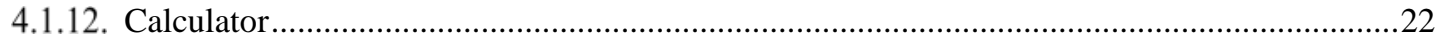

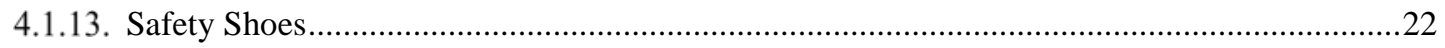

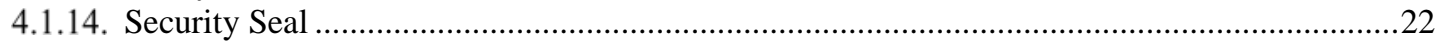

4.1.15. Approval Tags and Stickers .............................................................................................22

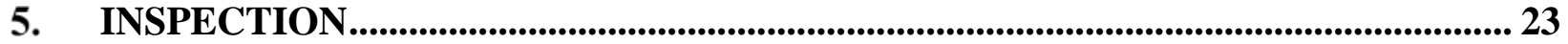

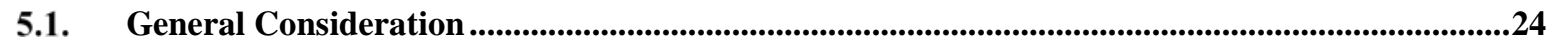

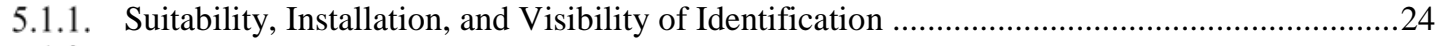

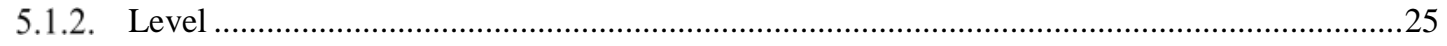

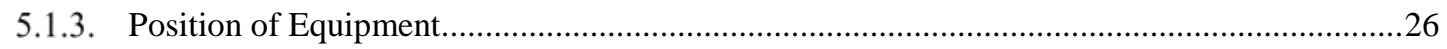

5.1.4. Location and Access …………………………………………………………………………....2

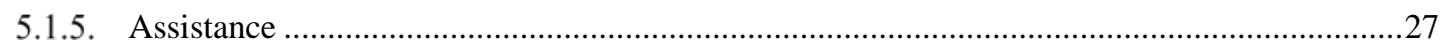

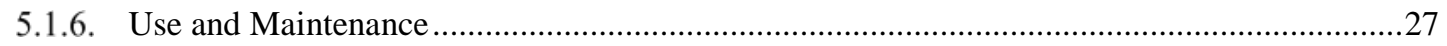

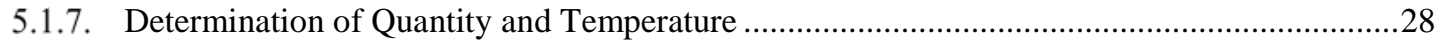

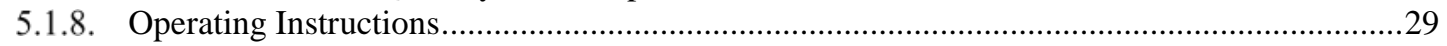

5.2. Indicating and Recording Elements.......................................................................................................29

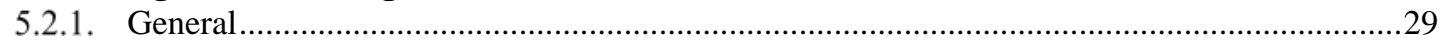

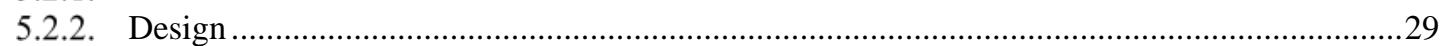

5.2.3. Selecting or Recording Grain or seed Type and Class.............................................................30

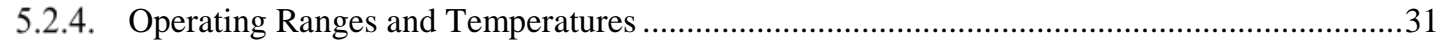

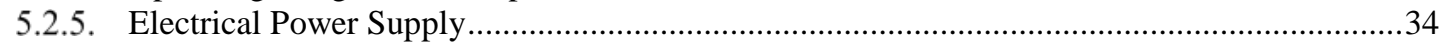

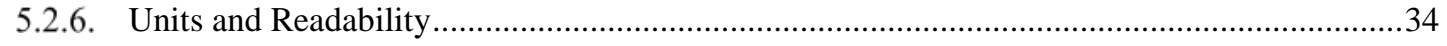

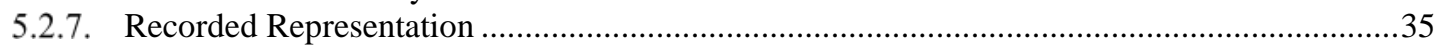

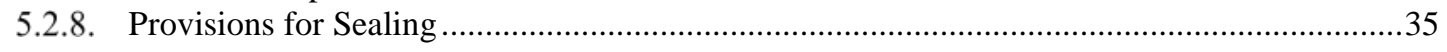

5.3. Marking Requirements..............................................................................................................................38

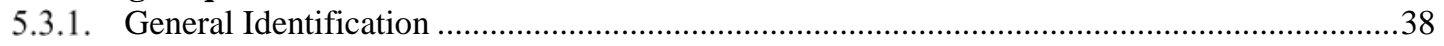

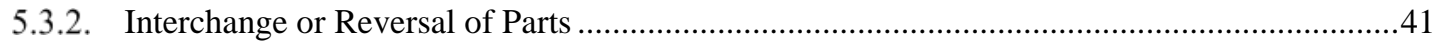

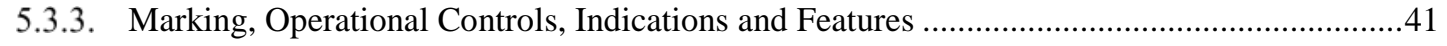

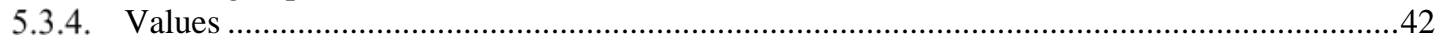

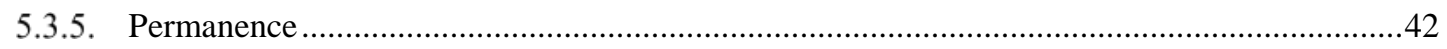

5.3.6. On Devices that Indicate or Record in more than One Unit .......................................................42

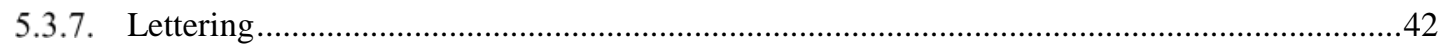

5.3.8. Other Devices not used for Commercial Measurements.......................................................43 


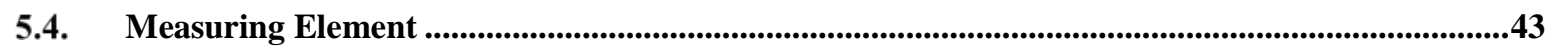

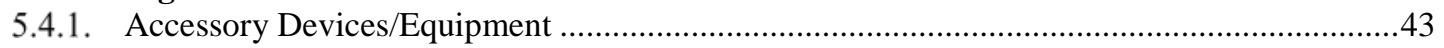

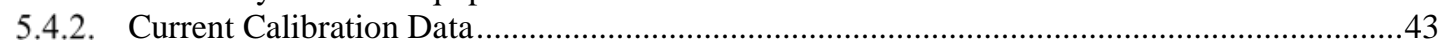

Figure 2-13. Calibration Data from a GMM Certificate of Conformance.................................................44

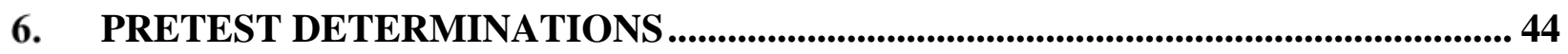

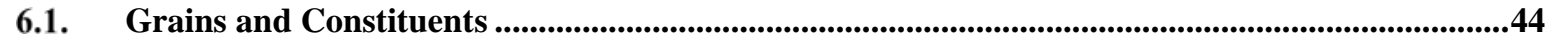

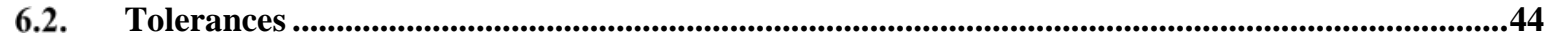

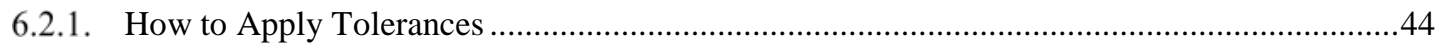

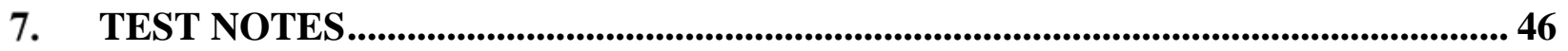

7.1. Official Grain Sample Maintenance, Test Methods and Documentation.........................................46

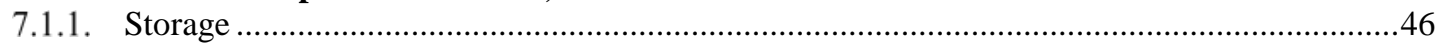

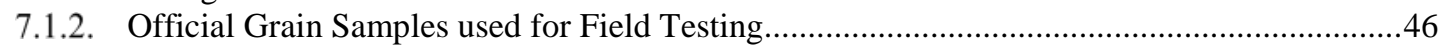

7.1.3. Warming Official Grain Samples in Preparation for Testing.....................................................46

7.1.4. Minimum Test and Maximum Number of Drops ....................................................................46

7.1.5. Preparation of the Official Grain Samples upon Arrival at the Test Site .................................47

7.1.6. Field Inspection and Test Method........................................................................................48

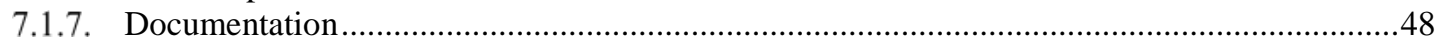

7.2. Official Grain Samples (Transfer Standards), Minimum Test, Minimum Sample Size...............49

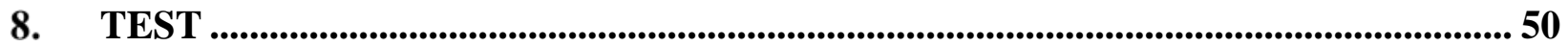

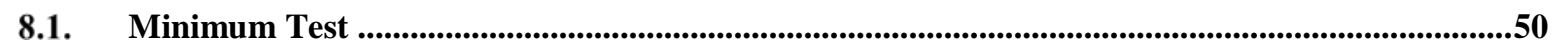

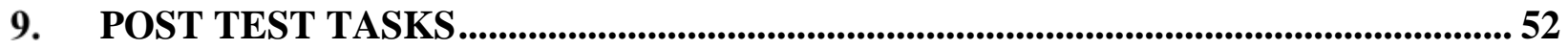

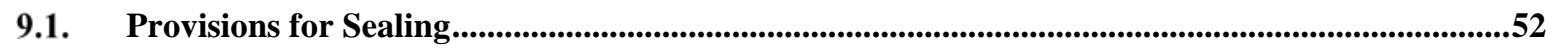

9.2. Record Results ........................................................................................................................................52

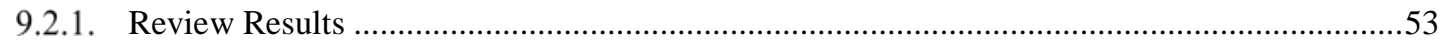

APPENDIX A. GRAIN MOISTURE METER SAMPLE TEST REPORT FORM .............. 1

APPENDIX B. GRAIN MOISTURE AIR-OVEN REFERENCE METHODS IN THE

UNITED STATES............................................................................................................................. 1

APPENDIX C. DETERMINING REFERENCE TEST WEIGHT PER BUSHEL VALUE

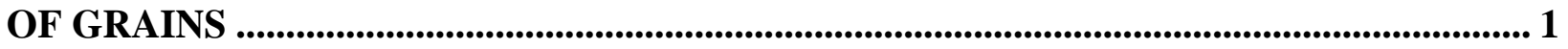




\section{Part 1: Laboratory Grain Sample Preparation and Testing}

\section{Scope}

Part 1 of this Handbook provides: (1) technical guidelines for determining the moisture content of grain samples using reference air-oven test procedures; (2) a description of the laboratory equipment needed to determine the moisture in grain; and (3) instructions for preparing the parent and working samples used to test commercial moisture meters and multi-constituent grain analyzers in accordance with NIST Handbook 44, "Specifications, Tolerances, and Other Technical Requirements for Weighing and Measuring Devices,” Section 5.56.(a) “Grain Moisture Meters (GMM).”

\section{General Guidance on Safety}

Many policies and regulations will vary among jurisdictions. It is essential that inspectors or service persons be aware of all safety regulations and policies in place in the laboratory and to practice their employers' safety policies. The safety reminders included in this manual contain general guidelines useful in alerting laboratory persons to the importance of taking adequate precautions to avoid personal injuries. These guidelines can only be effective in improving safety when coupled with training in hazard recognition and controls.

Always be familiar with emergency procedures BEFORE testing. After an emergency has developed, crucial time can be lost if emergency procedures are not known. Be familiar with the procedures to follow in the event of an equipment malfunction or the development of a dangerous situation with the equipment or in the vicinity of the laboratory when operating specialized testing equipment.

Be familiar with the nature of any product being dispensed by a device or being used in or near the laboratory. Know the emergency procedures to be followed when a spill of a hazardous product has occurred or a person has been exposed to the product. Knowledge of emergency procedures and related information should include the correct selection and use of fire extinguishers, the location of emergency shut-offs, and evacuation procedures.

Keep a list of emergency phone numbers handy at all times in a notebook or on a card. Examples of numbers to keep are the local fire department, emergency medical facility, and other appropriate public safety agencies. Prior to testing, carefully check the laboratory for safety hazards and take appropriate precautions including:

- Inspect all electrical cords and connections for damage to prevent electrical shock.

- Learn the nature of hazardous products used in or near the laboratory.

- Know the emergency evacuation routes for the laboratory.

- Use personal protection equipment appropriate for the laboratory and for particular testing.

- Wear safety shoes to prevent possible injury from falling weights, grain sample containers, and other equipment and to prevent slipping on wet or slick surfaces.

- Wear proper breathing apparatus, if necessary, for protection from dust and other airborne contaminants.

- Be sure that a first aid kit is available and that the kit is appropriate for the type of activity.

- Practice safe and proper lifting techniques.

- Use a lid opener if grain sample container lids are too tight to be removed comfortably by hand. Do not strain. Firmly grasp the container with good hand and wrist positioning; 
- Dry condensation from the outside of the grain sample container to prevent slippage and possible breakage of container and/or injury to feet and toes; and

- Watch for chips, cracks, or breakage of glass containers. If found, dispose of the container properly to prevent injury to the inspector. A damaged container may also affect the integrity of the grain sample moisture.

\section{Definitions}

\section{1. equilibrate}

To be in or bring about equilibrium. In the case of preparing grain samples for moisture testing, it refers to uniform distribution of moisture in the grain samples.

Note: Variations in moisture content may exist at the top, middle, and/or bottom of a onegallon working sample of grain. To reduce errors introduced by these variations, onegallon working samples of grain are not tested until they are refrigerated for at least 72 hours; this allows any moisture variations within the grain sample to equilibrate.

\section{2. laboratory standard meters}

Grain moisture meters of each type of meter used commercially in the State that are maintained in the laboratory and used to select and/or screen grains for testing and field use. These meters are used to determine the moisture values of grain samples; these values are compared to the moisture results obtained using the air-oven reference method and cannot exceed $0.3 \%$ if the grain sample is to be used to test the same moisture meter type in the field. Some laboratories also collect data on the laboratory meters that is shared with the meter manufacturer.

\section{3. naturally moist grains}

Grains that have not been artificially moistened by adding water to the grain after it has been harvested.

\section{4. parent sample}

The "parent sample" is a bulk sample of a given type of grain from which a "working sample” will be taken in order to create a set of official grain samples.

\section{5. test weight}

A measurement to determine the weight per volume (bulk density) of a particular lot of grain. For example, $\mathrm{kg} / \mathrm{hL}$ or lb/bu.

\section{6. working sample}

The "working sample" is taken from a "parent sample" of grain and used to create a set of official grain samples. See Example 1. "Preparing Samples for One Inspector to Conduct Field Testing” in Part 1. Section 9.1. "Official Grain Samples for Field Testing.” 


\section{Equipment}

This list includes a brief description of the equipment used in grain sample cleaning and mixing, test weight determination, and air-oven testing. The USDA, GIPSA Equipment Handbook provides additional information to include maintenance of the equipment included in this list. Pictures (figures) are included to provide examples of equipment used in some laboratories.

\subsection{Breathing Apparatus}

A mask or other appropriate apparatus used to prevent excessive inhalation of dust or other contaminants.

\subsection{Grain Sample Cleaning and Mixing Equipment}

\subsubsection{Automatic or Hand Sieves}

Automatic or hand sieves are used to remove larger or smaller materials from smaller samples of grain. See Figure 1-1. "Automatic or Hand Sieves."

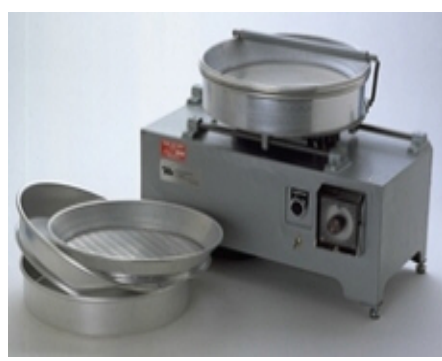

Figure 1-1. Automatic or Hand Sieves.

\subsubsection{Dockage Tester}

This device automatically removes and separates smaller or larger materials from large portions of grain. State grain laboratories use dockage testers to clean large samples of grain. After running samples through the dockage tester the samples of grain are cleaner and more uniform in size. See Figure 1-2. "Dockage Tester."

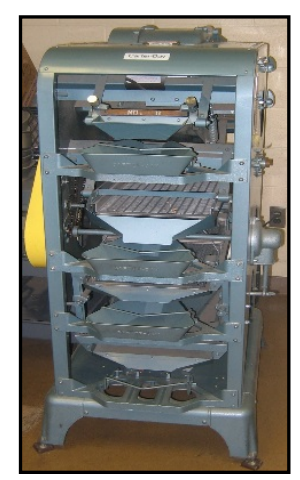

Figure 1-2. Dockage Tester

\subsubsection{Dividers}

Dividers are used to reduce a parent sample of grain to smaller, representative working samples. When a sample is placed in the divider it is separated into equal parts. Dropping grain through the divider several times also mixes the grain samples so that a representative sample can be tested. See Figure 1-3. "Dividers.”

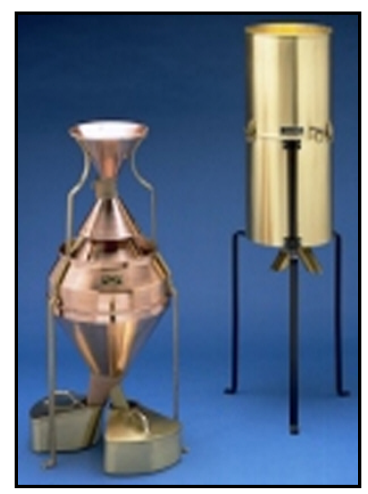

Figure 1-3. Dividers 


\subsection{Test Weight per Bushel Equipment}

This equipment is used to determine the test weight per bushel of the grain sample that is weighed. Figure 1-4. "Test Weight per Bushel Equipment” shows an example of a scale in which one quart of a grain sample is weighed on the scale that is designed to multiply the weight by 32 . Since there are 32 quarts to a dry bushel of grain, the scale provides a direct reading of the weight per bushel of the grain that is weighed.

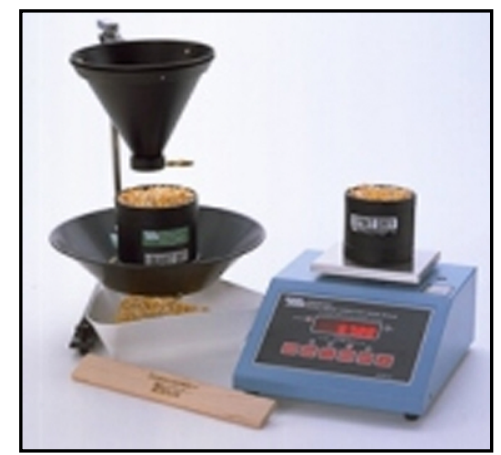

Figure 1-4. Test Weight per Bushel Equipment

\subsection{Basic Air-Oven Test Equipment}

Below is a list of basic equipment needed to perform single- and two-stage air-oven moisture testing and 72-hour air-oven tests for corn and beans. See Appendix B for additional information concerning air-oven test procedures. USDA, GIPSA Air-Oven Working Instructions provide a specific equipment list for each air-oven test described in the working instructions.

\subsubsection{Analytical Balance}

An analytical balance is used to take the final weight of the ground grain sample just before placing the samples in the oven for air-oven moisture testing and to get the weight of the sample after oven testing. The balance must be accurate to $0.1 \mathrm{mg}$. An example of an analytical balance is shown in Figure 1-5. “Analytical Balance.”

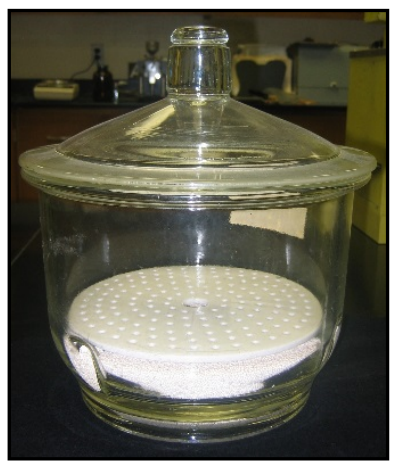

Figure 1-6. Glass Vacuum Desiccator with a Porcelain Plate.

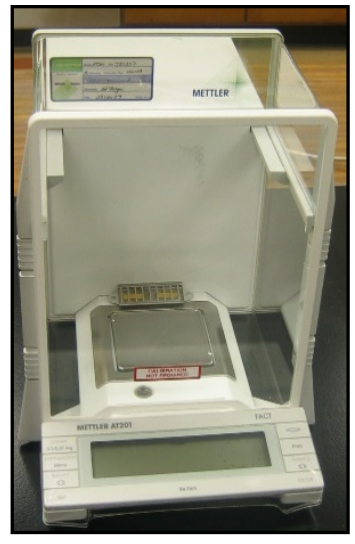

Figure 1-5. Analytical Balance.

\subsubsection{Glass Vacuum Desiccator}

A desiccator is used for cooling moisture dishes and ground grain samples after oven testing. Cooling grain samples in a desiccator is necessary to prevent the dry grain from absorbing moisture from the atmosphere during the cool-down period. The desiccator must be of the glass vacuum type and have an inside diameter of approximately $250 \mathrm{~mm}$, with a porcelain desiccator plate. Activated alumina, "molecular sieves" Type 4A desiccant must be placed in the bottom of the desiccator. See Figure 1-6. "Glass Vacuum Desiccator” with a Porcelain Plate. 


\subsubsection{Laboratory Mill}

A laboratory mill is a device used to grind the grain sample in preparation for air oven testing. Studies have shown that the use of different types of mills yields different test results. The laboratory mill should be the type listed in the USDA, GIPSA Airoven Moisture Reference Laboratory Work Instructions: The Wiley Intermediate Model Mill with a 20 mesh $(0.850 \mathrm{~mm})$ opening (Arthur H. Thomas Company, Philadelphia, Pennsylvania). See Figure 1-7. "Laboratory Mill.”

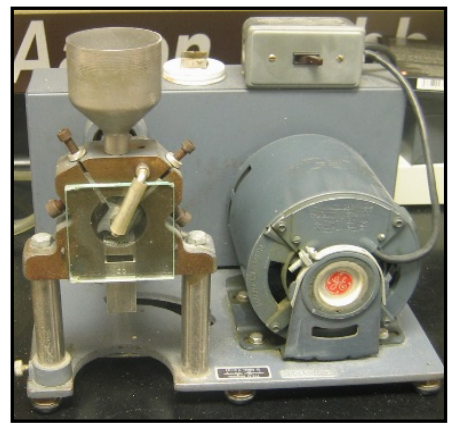

Figure 1-7. Laboratory Mill.

\subsubsection{Mechanical Convection (forced-draft) Oven}

Ovens are used to dry grain samples at the temperatures that are specified in the USDA, GIPSA Air-Oven Working Instructions. Ovens must be capable of maintaining a uniform temperature within $\pm 1{ }^{\circ} \mathrm{C}$ of the oven temperature specified for the specific air-oven test being conducted. See an example of a "Mechanical Convection (forced draft) Oven" in Figure 1-8. "Mechanical Convection (forced-draft) Oven.”

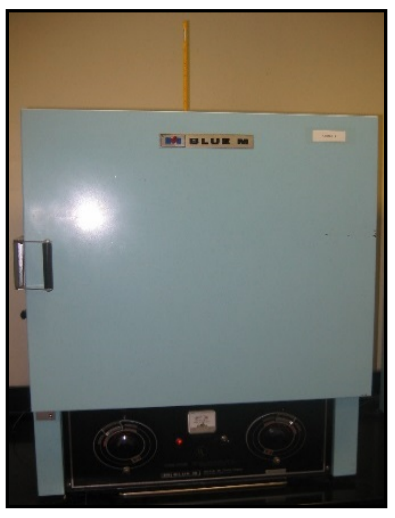

Figure 1-8. Mechanical Convection (forced-draft) Oven.

\subsubsection{Moisture Dishes (tins)}

Moisture dishes are used to hold ground grain samples. The moisture dish with a ground sample of grain is place in an oven for a time period and temperature specified in the test procedure. The moisture dishes are constructed of heavy aluminum, with a diameter of about $55 \mathrm{~mm}$ and a height of about $15 \mathrm{~mm}$. For high moisture corn, moisture dishes with a diameter of $92 \mathrm{~mm}$ and a height of $53 \mathrm{~mm}$ are needed. Intermediate size

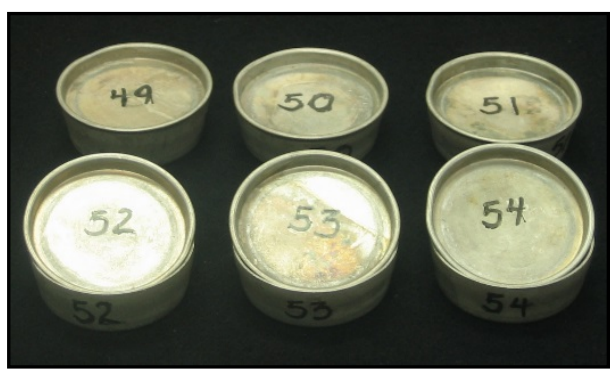

Figure 1-9. Moisture Dishes (tins). dishes with a diameter of $70 \mathrm{~mm}$ and a height of $30 \mathrm{~mm}$ may be used on large kernel samples. Follow the USDA, GIPSA air-oven working instructions (see Appendix B) to determine the correct size moisture dish for testing. The dishes must have fitted slip-in covers. Each individual dish and lid must be labeled with an identifying mark such as a unique number that is marked on both the lid and dish. Numbers engraved or stamped with a tool may be a better method for 
marking the dishes. Clearly labeling lids and dishes allows for tracking the dish tare weights over time and for storing dish weights to eliminate the need for reweighing after each use. See Figure 1-9. "Moisture Dishes (tins)."

\subsubsection{Thermometer}

An ASTM No. 96C, NIST traceable, partial-immersion thermometer is used to measure oven temperature. These thermometers are placed in the opening at the top of the oven with the immersion mark aligned with the oven ceiling. See Figure 1-10. "Partial Immersion Thermometers.” For 72-hour, air-oven testing, laboratories may consider using thermometers with charting capabilities in addition to the partial immersion thermometers to ensure the oven temperature is consistent during the entire test. Partial-immersion or digital Thermometers are also used to determine grain sample temperatures.

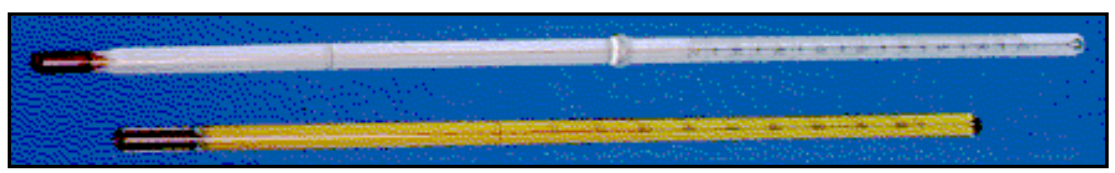

Figure 1-10. Partial-Immersion Thermometers.

\subsubsection{Top-loading Balance}

A top loading balance is used in grain sample preparation to weigh the required amount of grain that is placed in the moisture dishes for air-oven testing. The balance must be accurate to $0.01 \mathrm{~g}$. Examples of these balances are shown in Figure 1-11. "Top Loading Balances.”
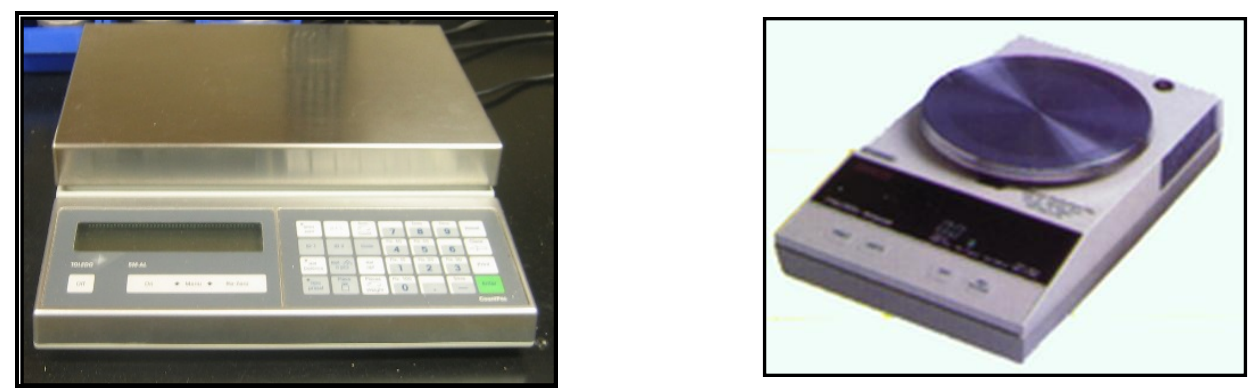

Figure 1-11. Top-loading Balances.

\section{General}

\subsection{Grain Handling}

When not required for immediate use, grain samples must remain in sealed bags or jars under refrigeration at a temperature of $1{ }^{\circ} \mathrm{C}$ to $3^{\circ} \mathrm{C}\left(34^{\circ} \mathrm{F}\right.$ to $\left.37^{\circ} \mathrm{F}\right)$. Prior to use, samples must be allowed to equilibrate to room temperature \pm 10 degrees of the ambient temperature before sample bags or jars are opened. This is necessary to prevent condensation which will have adverse effects on subsequent tests. 


\subsection{Air-Oven Test Procedures}

The laboratory must follow the air-oven test procedures in the USDA, GIPSA Technical Services Division, air-oven moisture laboratory working instructions. These procedures are included in training material provided by NIST, OWM or a copy may be obtained directly from:

USDA, GIPSA, FGIS

Telephone: 816-891-0401

National Grain Center

Fax: 816-872-1258

10383 N Ambassador Drive

Kansas City, MO 64153

See Appendix B for additional information concerning air-oven test procedures.

\subsection{Test Weight per Bushel Procedures}

To determine the reference test weight per bushel value of grains, the laboratory must follow the test weight procedures in Appendix $\mathrm{C}$ of this reference manual. This procedure may also be downloaded from NIST, OWM website at www.nist.gov/pml/wmd/. Select the link titled "Weights and Measures Connection Newsletter," then select the link titled "Newsletter Article Archives," then select "Grain Moisture Meters/NIR," then look for Series Number C-012 "Determining Reference Test Weight per Bushel Value of Grains.”

\section{Parent Grain Sample Preparation}

Grains used to test commercial grain moisture meters are collected from field locations within a weights and measures jurisdiction and brought to the jurisdiction's laboratory. In the laboratory, the grains are cleaned and stored in appropriate containers in preparation for testing. This section describes collection, cleaning, and proper storage of this grain.

\subsection{Collection}

Parent samples of "naturally moist grains" are typically collected at harvest time for each grain that is typically grown and traded in a state's jurisdiction. Low moisture and high moisture grain samples will be needed to test commercial grain moisture meters. As such, an attempt should be made to obtain samples covering a range of moistures for each grain type. (e.g., $13.0 \%$ and $16.0 \%$ moisture wheat samples). Low and high moisture ranges will vary per jurisdiction. Sufficient grain should be collected to provide enough samples needed to test all of the grain moisture meters in the jurisdiction. See Section 9, Example 1. "Preparing Samples for One Inspector to Conduct Field Testing" for guidance on the amount of grain to collect.

\subsection{Cleaning}

The parent samples are cleaned immediately upon receipt using dockage testers and automatic and/or hand sieves or equivalent grain or seed cleaning devices. Additional hand picking of the sample may be required to remove foreign material. Cleaned samples should consist of whole, sound seeds or kernels and be free of spoilage, dust, dirt, and foreign material. Follow the grain handling procedures in Part 1, Section 5.1. "Grain Handling" of this manual when cleaning the grain. 


\subsection{Storage and Labeling}

After samples are cleaned, mix each parent sample using a divider or other method to ensure that any portion of the parent grain sample is representative of the entire sample. After mixing, seal the grain in appropriate gallon storage containers (barrier, anti-static plastic bags or glass jars). See Figure 1-12. "Sample Storage-Glass Gallon Jars and Barrier, Anti-static Plastic Bags.” The samples are labeled with grain type, date of collection, collection point, and approximate moisture content and are assigned and labeled with a unique identification number for each grain sample. A number of jars or bags may be part of the parent sample so the unique identification number should include a sequential number following the identification number. For example, a unique ID number is 0714. Each jar or bag of grain with this ID number can be given the sequential number as follows 0714-1, 0714-2, 0714-3, etc. denoting this is a part of the parent sample 0714. Place these samples in refrigeration for 72 hours at $2{ }^{\circ} \mathrm{C}$ to $4{ }^{\circ} \mathrm{C}\left(35^{\circ} \mathrm{F}\right.$ to $\left.40{ }^{\circ} \mathrm{F}\right)$ prior to extracting working samples for testing to allow the moisture of the sample within the container to equilibrate.
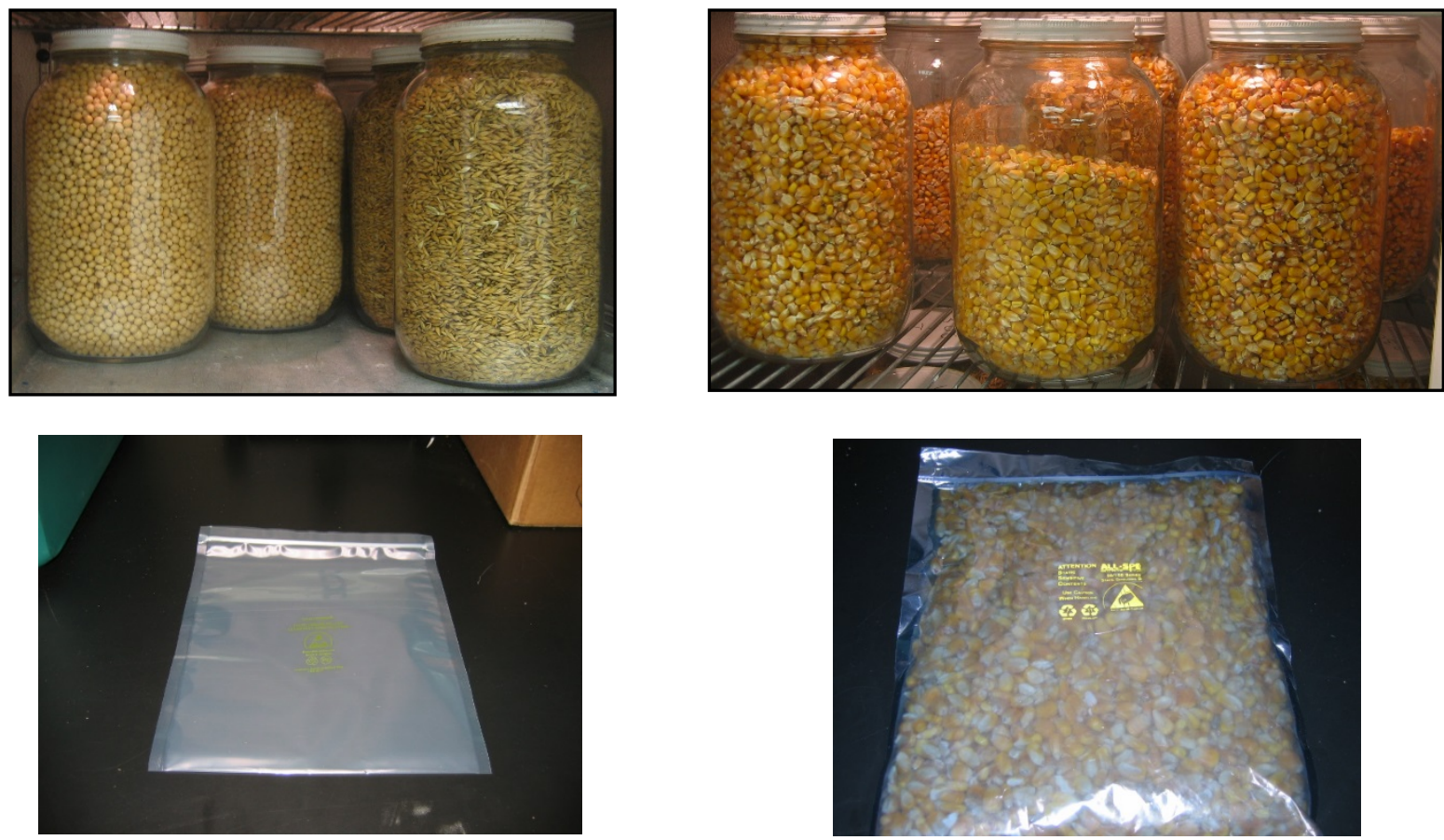

Figure 1-12. Sample Storage - Glass Gallon Jars and Barrier, Anti-static Gallon Plastic Bags.

\section{Working Sample Preparation}

Working samples are taken from a "parent sample" of grain and used to create a set of official grain samples. Since each gallon in the parent sample is representative of the entire parent lot, the first gallon working sample that is tested provides the information needed to determine if working samples within the parent sample lot can be used to create official grain samples. E.g., whether or not the parent sample meets laboratory standard meter moisture and reference air-oven moisture bias. 


\subsection{Laboratory Conditions}

When preparing and testing working samples, the laboratory must be maintained under the following conditions:

\subsubsection{Temperature:}

$68^{\circ} \mathrm{F}$ to $73^{\circ} \mathrm{F}\left(20^{\circ} \mathrm{C}\right.$ to $\left.23^{\circ} \mathrm{C}\right)$

\subsubsection{Maximum Rate of Change:}

$$
1.8^{\circ} \mathrm{F} / \mathrm{hr}\left(1.0^{\circ} \mathrm{C} / \mathrm{hr}\right)
$$

\subsubsection{Relative Humidity:}

$40 \%$ to $60 \%$

\subsection{Preparing Working Samples for Testing}

When you have collected enough grain to make testing practical, which is typically when you have enough grain samples to test reference air-oven moisture and laboratory standard meter moisture within a workday, remove grain samples that have been refrigerated for at least 72 hours at the conditions specified in Part 1, Section 6.3. "Storage and Labeling." Remove a one-gallon sample from each parent sample to serve as your working sample. Allow the sample to reach to within 10 degrees of the ambient temperature. Thoroughly mix each working sample by running it through a divider three times.

\section{Testing the Working Sample}

Each one-gallon working sample will be tested to determine a laboratory standard meter moisture; reference air-oven moisture; laboratory standard meter moisture vs. reference air-oven moisture bias; and test weight. Keep any remaining grain from the working sample in its original container (i.e., barrier, antistatic plastic bag or glass jar) during testing.

\subsection{Laboratory Standard Meter Moisture Measurements}

Determine the laboratory standard meter moisture of a sample from the one-gallon working sample selected for testing. Following meter manufacturers' instructions, place an appropriate amount of the working sample in each of the laboratory standard meters. Test each gallon working sample three times on each laboratory standard meter and calculate an average laboratory standard meter moisture value for each gallon working sample and record the results. Then return the remaining sample used to obtain a laboratory meter moisture to its appropriate container.

\subsection{Reference Air-Oven Moisture Measurements}

Upon completion of the laboratory standard meter moisture measurement described in Part 1, Section 8.1. "Laboratory Meter Moisture Measurements," immediately withdraw from each of the one-gallon working samples an amount sufficient to determine the reference air-oven moisture, as specified in the USDA, GIPSA air-oven test procedures. Record the average of three reference air-oven moisture results for each one-gallon working sample. See Appendix B "Grain Moisture Air-Oven Reference Methods in the United States” for additional information on the USDA GIPSA air-oven test procedures. 
Note: Keep ground grain samples tightly sealed and limit the time between grinding and weighing the grain samples to reduce error in reference air-oven moisture results.

\subsection{Laboratory Standard Meter Moisture vs. Reference Air-Oven Moisture Bias}

Calculate the bias between the average laboratory standard meter moisture measurement and the average reference air-oven moisture measurement for each one-gallon working sample. Record the results and retain this information in your laboratory records. Mark the containers of all the working samples in the parent lot that meet the bias requirements in Part 1, Section 8.4. "Requirements for Laboratory Standard Meter Moisture vs. Reference Air-Oven Moisture Bias." For example, an "A" that represents "Accepted" can be mark on the containers. Working samples and parent samples from which they were divided, which do not meet the criteria in Part 1, Section 8.4. "Requirements for Laboratory Standard Meter Moisture vs. Reference Air-Oven Moisture Bias” for all the laboratory standard meters may be discarded and record that the samples were discarded.

Note: The laboratory standard meter moisture and reference air-oven moisture bias is only determined on a one-gallon working sample from each parent sample. The result of this test applies to the entire parent sample.

\subsection{Requirement for Laboratory Standard Meter Moisture vs. Reference Air- Oven Moisture Bias}

For any working sample, the difference between the average standard laboratory meter moisture and the average reference air-oven moisture result shall not exceed plus or minus $0.3 \%$ moisture. This bias is applied to each laboratory standard meter.

Note: As meter technology improves (for example, the use of high frequency dielectric moisture meters with uniform algorithms across meters), variations between grain moisture meters will likely improve; however, grain variations may still influence meter moisture measurements.

\subsection{Determine the Test Weight}

While the reference air-oven testing is conducted, the working samples can be tested to obtain the test weight values. Test weight per bushel values are determined by following the procedures in Appendix C. "Determining Reference Test Weight per Bushel Value of Grains.” An average of 10 repeat test weight per bushel measurements is used to determine the test weight value for a working sample.

\subsection{Records}

Maintaining appropriate laboratory records provides an inventory of the grains and moisture ranges of those grains. This aids the laboratory in making any necessary changes to sample collection. Maintaining records of field data provides evidence of the integrity of the field samples. Records for all parent and working samples and field samples must be maintained in the laboratory. At a minimum, records must include:

\subsubsection{Parent and Working Samples}

a. grain type; 
b. identification number;

c. meter moisture result (the measurement of a one-gallon working sample applies to the entire parent sample lot);

d. air-oven moisture results;

e. meter moisture and air-oven moisture bias result (the measurement of a onegallon working sample applies to the entire parent sample lot);

f. test weight results; and

g. whether or not a parent sample lot was discarded after testing.

\subsubsection{Field Samples}
a. identification number of field samples issued;
b. date field samples were issued;
c. date field samples returned;
d. retested oven results; and
e. number of times field samples were warmed, opened, and dropped.

\section{Selecting and Preparing Official Grain Samples}

Make official grain samples from the one-gallon working samples that have an air-oven moisture vs. meter moisture bias that meets the requirements of Part 1, Section 8.4. "Requirements for Laboratory Meter Moisture vs. Air-Oven Moisture Bias" and were tested and have an assigned value for airoven moisture and test weight. The reference air-oven moisture and laboratory standard meter moisture bias is a one-time test and the values are assigned to all working samples within a parent sample based on the test results of a one-gallon working sample. But, it is necessary to test each gallon working sample within a parent sample for air-oven and test weight per bushel to avoid changes in moistures within the individual gallon working samples. These tests must be performed just prior to issuing the grain samples for field testing.

\subsection{Official Grain Samples for Field Testing}

Official grain samples used for field testing must be the grains that are representative of the grain types and moisture ranges normally traded in a jurisdiction. A one-gallon working sample of high moisture grain and a one-gallon working sample of the same grain type with a low moisture are selected for each grain type to prepare official grain samples. Each gallon working sample is divided into three or more official grain samples with a high moisture content and three or more official grain samples with a low moisture content for each grain type. (See Example 1. "Preparing Samples for One Inspector to Conduct Field Testing.”)

Samples are prepared by following these Steps: 
If the working samples are mixed and tested in accordance with Part 1, Section 8 "Testing the Working Sample,” on the same day that official grain samples are prepared, follow Part 1, Section 9.1, Step c, below

If the working samples were recently mixed and tested in accordance with Part 1, Section 8 "Testing the working sample" and then refrigerated, allow the sample to reach within 10 degrees of the ambient temperature, then follow Part 1, Section 9.1. "Official Grain Samples for Field Testing,” Steps a and c below.

If there has been a significant lapse of time since a refrigerated working sample has been tested in accordance with Part 1, Section 8 "Testing the Working Sample,” repeat test in Part 1, Section 8.2. "Reference Air-Oven Moisture Measurements" and Section 8.5. "Determine the Test Weight” then follow Part 1, Section 9.1. "Official Grain Samples for Field Testing,” Step c, below.

If it is the first time a working sample is tested, allow the sample to reach within 10 degrees of the ambient temperature, then follow Part 1, Section 9.1. "Official Grain Samples for Field Testing,” Steps a to c below.

a. Thoroughly mix each gallon working sample for each grain type and moisture content by running it through a divider three times.

b. Test the working sample in accordance with Part 1, Section 8.1. "Laboratory Standard Meter Moisture Measurements” to 8.5. "Determine the Test Weight” of this manual.

c. Extract three grain samples of sufficient size from each grain type and moisture level of each working sample. Place the official grain samples in the appropriate containers (See Part 2, Section 4.1.9. “Official Grain Samples.”) and keep any additional portions for lab verification. Refrigerate the samples until distributed to field inspection staff. (See Example 1. "Preparing Samples for One Inspector to Conduct Field Testing.")

Example 1. Preparing Official Grain Samples for One Inspector to Conduct Field Testing.

\begin{tabular}{|c|c|c|c||}
\hline $\begin{array}{c}\text { Working Grain } \\
\text { Samples (Number } \\
\text { of Gallons) }\end{array}$ & Grain Type & Moisture Content & $\begin{array}{c}\text { Field Samples - } \\
\text { Number of Pint or } \\
\text { Quart, Jars or Bags }\end{array}$ \\
\hline \hline 1 & Corn & $18.3 \%$ (High) & 3 \\
\hline 1 & Corn & $15.0 \%$ (Low) & 3 \\
\hline 1 & Wheat & $16.0 \%$ (High) & 3 \\
\hline 1 & Wheat & $13.5 \%$ (Low) & 3 \\
\hline 1 & Soybeans & $16.2 \%$ (High) & 3 \\
\hline 1 & Soybeans & $14.0 \%$ (Low) & 3 \\
\hline
\end{tabular}

Official grain samples must be of sufficient size for meter testing; this is typically one pint or one quart. Different meter models may require different sample sizes. Place the official grain samples in glass jars or poly bags and mark the official grain samples with the following information:

a. working sample ID number; 
b. grain type;

c. date the official grain sample was prepared;

d. reference moisture value (as determined by the USDA GIPSA Air-Oven Method);

e. test weight value; and

f. space for the inspector to record number of times the sample was warmed, opened, and dropped.

Next, return the field samples and the remaining portion of the parent sample to refrigeration until needed by field inspectors.

\subsection{Time Lapse}

To prevent moisture loss and/or deterioration of the official grain samples that may occur over time, official grain samples should be issued to field inspectors as soon as practical after testing and preparation. If substantial time has elapsed from the initial determination of moisture and test weight measurements or there are concerns that these values have changed, another working sample from the parent sample should be tested to obtain a current moisture and test weight value and then used to prepare another set of official grain samples, prior to issuing the official grain samples for use in field testing.

\section{Retesting and Reusing Official Grain Samples}

Official grain samples are used for a limited number of drops when testing grain moisture meters as specified in Part 2, Section 7.1.4. "Minimum Test and Maximum Number of Drops," Paragraph d. After a grain sample is used for the specified maximum number of drops, the samples must be returned to the laboratory for retesting and/or reuse.

\subsection{Retesting Samples}

In the event that problems or concerns arise with any field tests conducted with a given official grain sample, perform an air-oven test on those official grain samples returned to the laboratory. This will provide evidence of whether or not the official grain sample moisture was maintained during field testing.

Periodically retest official grain samples that are returned to the laboratory after use to monitor and maintain a check on the system. If retesting reveals that moisture values are changing significantly, this may indicate a need to change field handling procedures; reduce the permitted number of drops; or take after actions to ensure that grain samples are maintaining their stability during field testing.

Keep a record of all retest results and action taken to resolve issues resulting from retests.

\subsection{Reusing Samples}

Official grain samples may be reused if they are returned to the laboratory in good condition. To reuse these samples, recombine official grain samples of the same type and identification number in a gallon container and mix the grain. Next, place the sample in 
Part 1: Laboratory Grain Sample Preparation and Testing

refrigeration as specified in Laboratory Grain Sample Preparation and Testing, Part 1, Section 6.3. "Storage and Labeling." After 72 hours, the working sample can be tested for reference air-oven moisture and test weight and then reissued as official grain samples. 


\section{PART 2: Field Inspection and Evaluation}

\section{EPO No. XX}

\section{Scope}

Part 2 of this Handbook provides technical guidelines for the field evaluation of grain moisture meters and multi-constituent grain analyzers that measure moisture in accordance with NIST Handbook 44, Section 5.56.(a) "Grain Moisture Meters" for field testing using air-oven reference method transfer standards. The requirements of NIST Handbook 44 are grouped into the following sections as outlined in NIST Examination Procedure Outlines:

- Safety

- Definitions

- Equipment

- Inspection

- Pretest Determination

- Test notes

- Test

- Post Tasks

\section{General Guidance on Safety}

Many policies and regulations will vary among jurisdictions. It is essential that the inspector or service persons be aware of all safety regulations and policies in place at the inspection site and to practice their employers' safety policies. The safety reminders included in this manual contain general guidelines useful in alerting inspectors and service persons to the importance of taking adequate precautions to avoid personal injuries. These guidelines can only be effective in improving safety when coupled with training in hazard recognition and controls.

Always be familiar with emergency procedures BEFORE beginning an inspection. After an emergency has developed, crucial time can be lost if emergency procedures are not known. Be familiar with the procedures to follow in the event of an equipment malfunction or the development of a dangerous situation with the equipment or in the vicinity of the inspection site when operating specialized testing equipment.

Be familiar with the nature of any product being dispensed by a device or being used in or near the inspection area. Know the emergency procedures to be followed when a spill of a hazardous product has occurred or a person has been exposed to the product. Knowledge of emergency procedures and related information should include the correct selection and use of fire extinguishers, the location of emergency shut-offs, and evacuation procedures.

Keep a list of emergency phone numbers handy at all times in a notebook or on a card. Examples of numbers to keep are the local fire department, emergency medical facility, and other appropriate public safety agencies. Prior to inspection and evaluation of a moisture meter carefully check the site for safety hazards and take appropriate precautions including:

- Inspect all electrical cords and connections for damage to prevent electrical shock. 
- Learn the nature of hazardous products used at or near the inspection site.

- Know the emergency evacuation routes at each inspection site.

- Use personal protection equipment appropriate for the site and for the particular job.

- Wear safety shoes to prevent possible injury from falling weights, grain sample containers, and other equipment and to prevent slipping on wet or slick surfaces.

- Wear proper breathing apparatus, if necessary, for protection from dust and other airborne contaminants.

- Wear a hard hat for protection from overhead hazards, when appropriate.

- Be sure that a first aid kit is available and that the kit is appropriate for the type of activity.

- $\quad$ Practice safe and proper lifting techniques.

- Use a lid opener if grain sample container lids are too tight to be removed comfortably by hand. Do not strain. Firmly grasp the container with good hand and wrist positioning.

- Dry condensation from the outside of the grain sample container to prevent slippage and possible breakage of container and/or injury to feet and toes.

- Watch for chips, cracks, or breakage of glass containers. If found, dispose of the container properly to prevent injury to the inspector. A damaged container may also affect the integrity of the grain sample moisture.

- Be sure all equipment being transported by the inspector or service technician is properly secured in the vehicle.

- Practice defensive driving when traveling between sites.

\section{Definitions}

\section{1. audit trail}

An electronic count and/or information record of changes to the values of the calibration or configuration parameters of a device.

[NIST Handbook 44]

\section{2. cereal grain and oil seeds}

Agricultural commodities including, but not limited to, corn, wheat, oats, barley, flax, rice, sorghum, soybeans, peanuts, dry beans, safflower, sunflower, fescue seed, etc.

[NIST Handbook 44]

\section{3. constituent}

A component of a grain, such as protein, oil, starch, or moisture that a grain analyzer is capable of measuring.

\section{4. back-up sample}

An official grain sample used only when a change is suspected in the moisture content of an official grain sample that will affect the test results.

\section{5. drop}

Each time a grain sample is passed through the measurement cycle of a moisture meter. 


\section{6. grain calibration}

A quantitative standardization established by a meter manufacturer for a specific grain and meter type.

\section{7. grain moisture meter}

Any device indicating either directly or through conversion tables and/or correction tables the moisture content of cereal grains and oil seeds. Also termed "moisture meter."

[NIST Handbook 44]

Note: This Handbook is primarily oriented toward the preparation and use of samples for testing GMMs covered under NIST Handbook 44, Section 5.56.(a). However, Part 1 and some sections of Part 2 of this handbook may be used to develop official grain samples for use in evaluating meters that require conversion and correction tables to determine grain moisture content. Part 2, Sections 5.1. "Indicating and Recording Elements" to 9.Post Test Tasks" are requirements from NIST Handbook 44, Code 5.56.(a) and are not applicable to meters that require conversion and correction tables to determine grain moisture content.

\section{8. kind of grain}

Corn as distinguished from soybeans as distinguished from wheat, etc.

[NIST Handbook 44]

\section{9. moisture content (wet basis)}

The mass of water in a grain or seed sample (determined by the reference method) divided by the mass of the grain or seed sample expressed as a percentage (\%).

[NIST Handbook 44]

\subsection{0. opened}

Each time grain is removed from and returned to the sample storage container, it has been "opened” once.

Note: The time required to change lids to enable thermometer insertion should be so short as not to constitute an opening.

\subsection{1. official grain samples}

Grain or seed used by the official as the official transfer standard from the reference standard method to test the accuracy and precision of grain moisture meters.

[NIST Handbook 44]

\subsection{2. grain sample}

That portion of grain or seed taken from a bulk quantity of grain or seed to be bought or sold and used to determine the moisture content of the bulk.

[NIST Handbook 44] 
Part 2: Field Inspection and Evaluation

\subsection{3. security seal}

A uniquely identifiable physical seal, such as a lead-and-wire seal or other type of locking seal; a pressure-sensitive seal sufficiently permanent to reveal its removal; or similar apparatus attached to a weighing or measuring device for protection against or indication of access to adjustment.

[NIST Handbook 44]

\subsection{4. specification}

A requirement usually dealing with the design, construction, or marking of a weighing or measuring device. Specifications are directed primarily to the manufacturers of devices. [NIST Handbook 44]

\subsection{5. test site}

A location housing a grain moisture meter or accessory device, which is subject to official inspection and testing.

\subsection{6. test weight}

A measurement to determine the weight per volume (bulk density) of a particular lot of grain. For example, kg/hL or lb/bu.

\subsection{7. tolerance}

A value fixing the limit of allowable error or departure from true performance or value. [NIST Handbook 44]

\subsection{8. warmed}

Each time a sample of grain is brought to within $10^{\circ} \mathrm{F}$ of the ambient temperature, it has been "warmed."

\section{Field Equipment and Grain Samples}

A brief description of the equipment needed for the field evaluation and testing of grain moisture meters are included in this section. Pictures (figures) are included to provide examples of equipment used in some states. See Figure 2-1. "Apparatus, Equipment and Documents for Field Testing of Grain Moisture Meters.” 


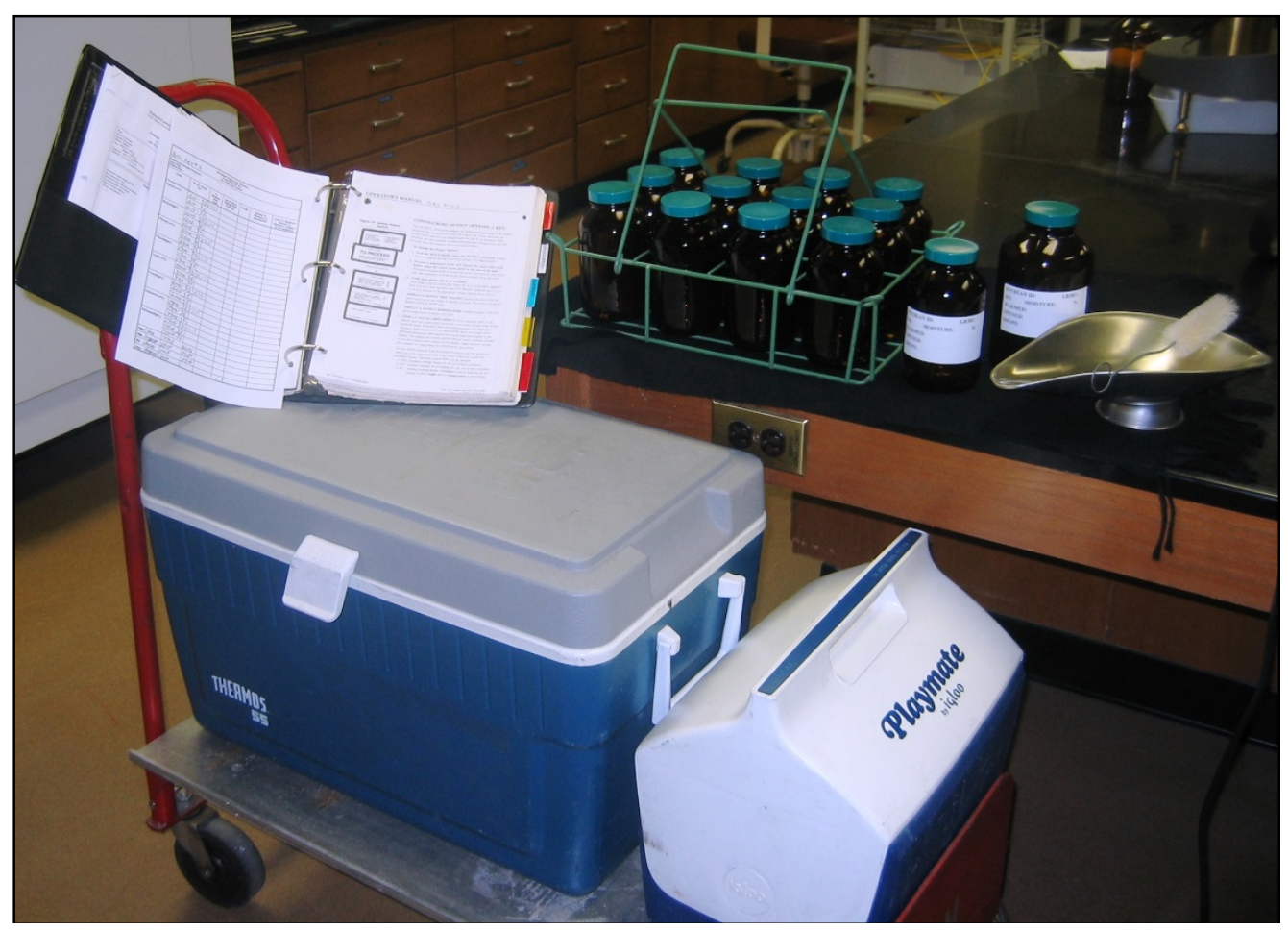

Figure 2-1. Apparatus, Equipment, and Documents for Field Testing of Grain Moisture Meters.

\subsection{Apparatus and Equipment}

\subsubsection{Breathing Apparatus}

A mask or other appropriate apparatus used to prevent excessive inhalation of dust or other contaminants.

\subsubsection{Thermometer}

Thermometers can be digital or liquid-in-glass and must meet NIST Handbook 105-6, "Specifications and Tolerances for Thermometers," requirements. These thermometers are used to monitor the grain sample temperatures. (see Figure 2-2. "Examples of Thermometers"). A partial immersion thermometer is a thermometer that is designed to be used partially immersed in fluid or product typically to a designated immersion mark on the thermometer. If using a partialimmersion thermometer it should be placed into the grain sample to the submersion line on the thermometer. 

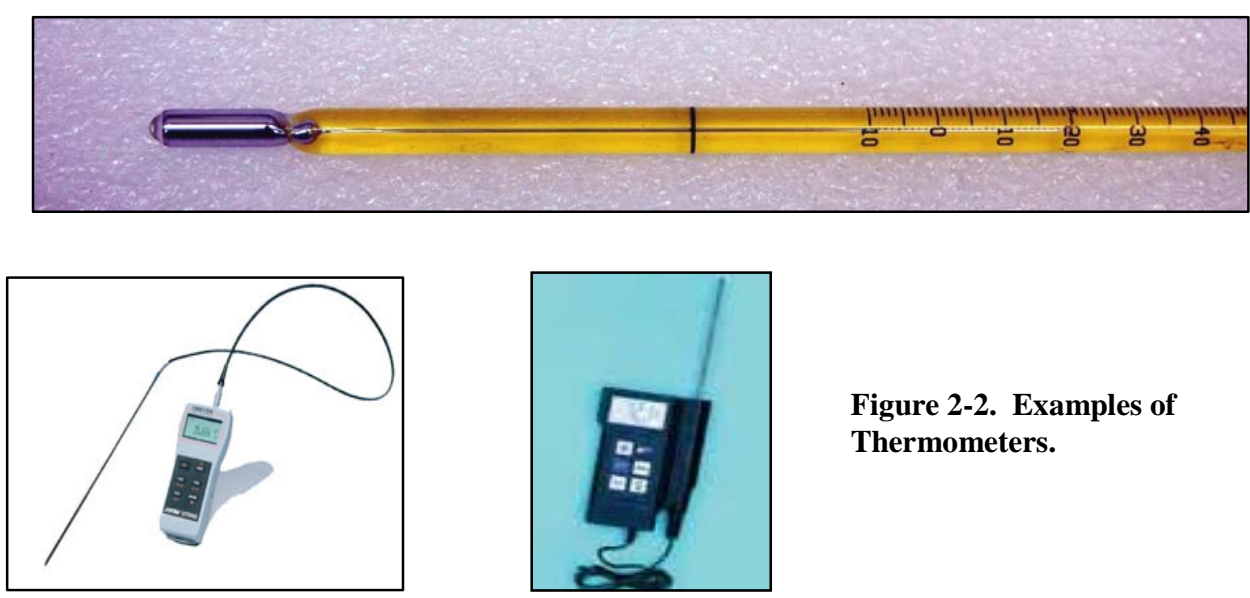

Figure 2-2. Examples of Thermometers.

\subsubsection{Container}

A container of sufficient size may be used to safely carry accessory equipment.

\subsubsection{Cooler}

A cooler is needed for the sample jars of grain after removing the jars from the refrigerator. This will allow them to stabilize to ambient temperature and minimize exposure to temperature extremes and fluctuations. Ice must not be used in the cooler since it can cause condensation on sample jars and potentially affect the moisture content of the grain and stability of the sample. The cooler must be of adequate size to accommodate the number of samples that will be used for testing. See Figure 2-1. "Apparatus, Equipment, and Documents Field testing of Grain Moisture Meters.”

\subsubsection{Fire Extinguisher}

Know the proper use and selection of fire extinguishers for a given application. Contact your local fire department for current information and training.

\subsubsection{First Aid Kit}

An appropriate first aid kit should be maintained in your vehicle. Consideration should be given to the type of work that the inspector, or service person typically performs and the types of hazards typically encountered in these types of activities. Items in addition to those contained in a basic first aid kit may need to be added to address the potential hazards which may be encountered by the person who will be most likely to use the first aid kit. Check with your local OSHA office or with your departmental safety officer for input on the items to be included in each kit.

\subsubsection{Portable Refrigerator}

Portable refrigerators are used to keep the samples cold before and after testing to help maintain grain sample stability and condition. A connection to an energy source is needed to maintain cold conditions. For example, some portable refrigerators may be attached to the cigarette lighter in a motor vehicle. See an example in Figure 2-3. "Portable Refrigerator." 


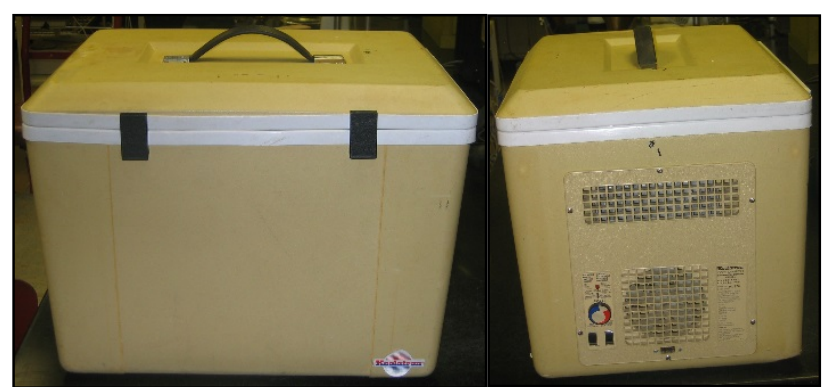

Figure 2-3. Portable Refrigerator (front and side views).

\subsubsection{Grain Sample Racks}

Racks are used to carry standard grain samples from meter to meter during testing.

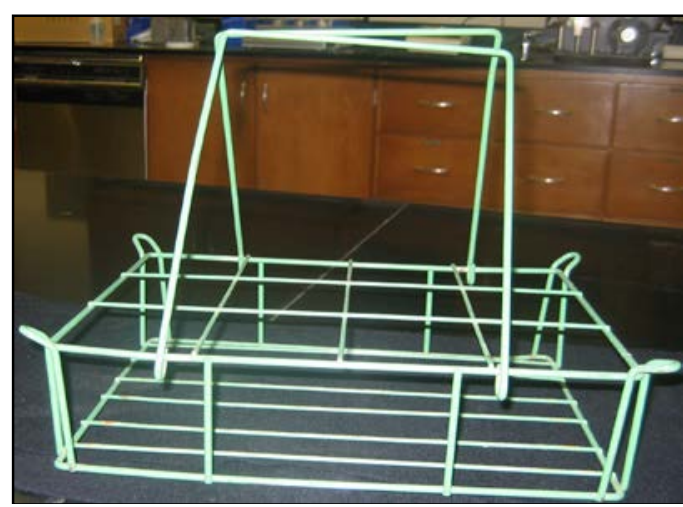

Figure 2-4. Grain Sample Rack.

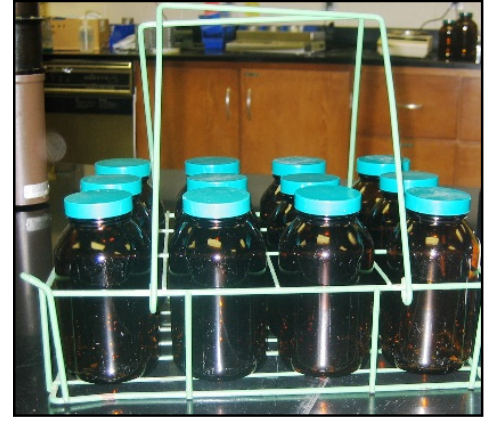

Figure 2-5. Pint Grain Samples.

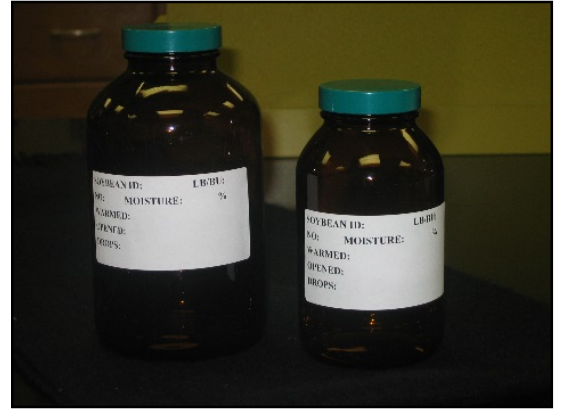

Figure 2-6. Labeled Quart and Pint Grain Samples.

\subsubsection{Official Grain Samples}

At least three samples per grain type and moisture level (one high and one low moisture grain sample) are used to test meters; jurisdictions may choose to use additional official grain samples. The official grain samples must be stored in glass jars with lids or anti-static plastic bags. For additional details on preparation and handling of grain samples, see Part 1, Section 9.1. "Official Grain Samples for Field Testing” and Part 2, Section 7.1.2. "Official Grain Samples for Field Testing." Examples of storage containers are shown in 
Figures 2-5. "Pint Grain Samples” and 2-6. "Labeled Quart and Pint Grain Samples.”

\subsubsection{Personal Protection Equipment (PPE)}

The appropriate PPE for testing grain moisture meters may include goggles or safety glasses, hardhats, safety shoes, and other equipment deemed necessary by your organization to complete the tests.

\subsubsection{Two-inch Aluminum Angle Gage}

Use a ruler or other aid to verify the distance between the kettle and funnel height of the test weight per bushel equipment. A two-inch aluminum angle gage that rests on top of the kettle and maintains a perpendicular orientation to the top edge of the funnel is recommended as an aid in making this measurement. See Figure 2-7. "Aluminum Angle Gage” for an example of a gage used to measure the distance between the kettle and funnel height.

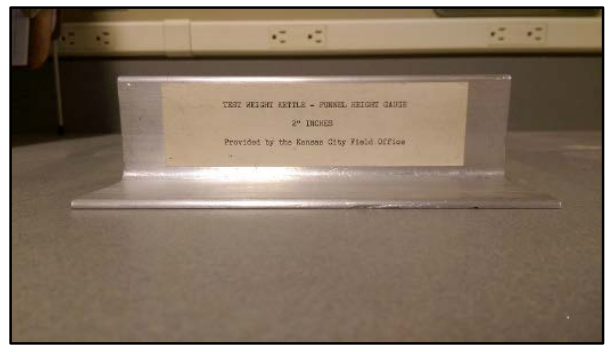

Figure 2-7. Aluminum Angle Gage.

\subsubsection{Calculator}

A calculator may be necessary to assist with error and other test calculations.

\subsubsection{Safety Shoes}

Safety shoes to prevent possible injury from falling weights or equipment and also to provide protection from slippage

\subsubsection{Security Seal}

A uniquely identifiable physical seal, such as a lead-and-wire seal or other type of locking seal, a pressure-sensitive seal sufficiently permanent to reveal its removal, or similar apparatuses attached to a weighing or measuring device for protection against or indication of access to adjustment.

[NIST Handbook 44]

\subsubsection{Approval Tags and Stickers}

Tags or stickers applied to grain moisture meters to indicate approval or rejection of the meter and may include the date of inspection. Devices may be tagged and/or removed from service due to large testing errors that exceed the allowable tolerances. 


\section{Inspection}

The most current requirements of NIST Handbook 44, Section 5.56.(a) must be applied when inspecting grain moisture meters in accordance with this manual. NIST Handbook 44, Section 5.56.(a) applies to all NTEP meters and meters manufactured or placed into service after January 1, 1998. Sections 5.1. "General Consideration," to 9. "Post Test Tasks," are the requirements of NIST Handbook 44, Section 5.56.(a) used to inspect and test grain moisture meters using air-oven transfer standards.

\section{Safety Reminders}

\section{Location.}

- Carefully examine the inspection site prior to beginning an inspection and testing procedure. Look for potentially dangerous situations such as:

o wet areas which may be slippery (see also Wet/Slick Conditions),

0 adjacent activities which may contribute a potential hazard to the inspection,

0 obstructions in the area which may prove to be safety hazards (e.g., objects on the ground which the inspector might trip over, objects in the path of the inspector to and from the device being tested, exits blocked by test equipment or vehicles, etc. - see also Obstructions),

o pedestrian or vehicle traffic (see also Traffic),

o steep or narrow stairways,

o overhead hazards (e.g., feed bins, loading rack equipment, low-hanging beams in feed mills and warehouses, overhead activities, low doorways, etc. - see also Overhead Hazards),

o lack of or defective handrails, and

o loose or exposed wiring (see also Electrical Hazards). Use great care when moving around and working in areas in which these potential hazards are present.

o When using flammable products (e.g., testing metering devices), note the location of the fire extinguisher, emergency shut-offs, etc. prior to beginning the inspection.

\section{Electrical Hazard.}

- Be particularly aware of potential electrical hazards in or near the inspection site when testing electronic devices or working in the vicinity of electrical equipment.

- Loose or exposed wiring and a frayed or worn electrical cord should be brought to the attention of management at the inspection site.

- Avoid standing on wet surfaces unless the electrical equipment is properly insulated and grounded. 


\section{Safety Reminders (continued)}

\section{Obstructions.}

- Care should be taken to avoid injury from obstructions in the work area during the course of an inspection. Obstructions which might prove to be safety hazards include:

o objects on the ground which the inspector might trip over,

0 objects in the path of the inspector to and from the device being tested,

o steep or narrow stairways, and

o exits blocked by test equipment or vehicles, etc.

\section{Overhead Hazards.}

- Note any overhead hazards such as feed bins, loading rack equipment, low-hanging beams in feed mills and warehouses, activities overhead, and low doorways prior to the inspection.

- Take precautions, such as wearing a hardhat, to avoid potential injuries as the situation dictates.

\section{Wet/Slick Conditions.}

- Caution should be exercised when working in wet, slippery, or icy conditions to avoid slipping or possible injury from electrical sources.

- Shoes with non-skid soles should be worn to provide adequate traction to prevent slipping.

- Be sure all equipment being transported by the inspector or service technician is properly secured in the vehicle.

- Practice defensive driving when traveling between sites.

\subsection{General Consideration}

This section includes NIST Handbook 44 General Codes requirements used to determine if the device is suitable for its use; installed appropriately; and its markings are readily observable and understood.

\subsubsection{Suitability, Installation, and Visibility of Identification}

[Code References: NIST Handbook 44, Section 1.10. General Code, G-UR.1.1., G-UR.1.2., G-UR.2.1., UR.2. and G-UR.2.1.1.]

Commercial equipment shall be:

a. suitable for the service in which it is used with respect to the elements of its design including but not limited to its weighing capacity (for weighing devices), its computing capability (for computing devices), its rate of flow (for liquidmeasuring devices), the character, number, size, and location of its indicating or recording elements, and the value of its smallest unit and unit prices 


\section{Guidance:}

$\square$ Current calibrations for a GMM are located in its Certificate of Conformance. Verify that the moisture meter has current grain calibrations for all grains being traded at the location.

b. suitable for the environment in which it is used, including, but not limited to, the effects of wind, weather, and RFI. G-UR.1.2.

\section{Guidance:}

Grain Moisture meters have specified operating conditions. Verify that a moisture meter is being used in accordance with the temperature ranges specified in the NTEP CC.

$\square \quad$ If there are sources of RFI near the moisture meter, look for any fluctuations in reading results during testing that affect the measurements.

c. a device shall be installed in accordance with the manufacturer's instructions, including any instructions marked on the device. A device installed in a fixed location shall be installed so that neither its operation nor its performance will be adversely affected by any characteristic of the foundation, supports, or any other detail of the installation. G-UR.2.1.

\section{Guidance:}

$\square$ Review the manufacturer's operating instructions to verify that the moisture meter installation is appropriate.

d. equipment shall be installed in such a manner that all required markings are readily observable. G-UR.2.1.1.

\section{Guidance:}

$\square \quad$ Ensure that you are able to view the marking such as serial number, model number and other identifiable markings needed to operate or identify the grain moisture meter.

\subsubsection{Level}

[Code References: NIST Handbook 44, Section 5.56.(a) GMM, S.2.3, UR.3.8.]

A meter shall be equipped with a level indicator and leveling adjustments if its performance is changed by an amount greater than the applicable tolerance when the meter is moved from a level position to a position that is out of level in any upright direction by up to $5 \%$ (approximately three degrees). The levelindicating means shall be readable without removing any meter parts requiring a tool. S.2.3.

a. If equipped with a level indicator, a meter shall be maintained in a level condition. ..UR.3.8.

\section{Guidance:}

Figure 2-8. “A Level Indicating Means Showing an In-level Condition” shows one type of level indicating means (a level bubble) on a grain moisture meter. Other 
level indicating means may be available on grain moisture meters. Using the level indicating means on a meter, determine that the device is in level prior to testing.

If no level indicating means is available, place shims under the meter to raise it to a position out of level in any upright direction $5 \%$ or approximately three degrees, then verify that the performance has not changed in the non-level condition.

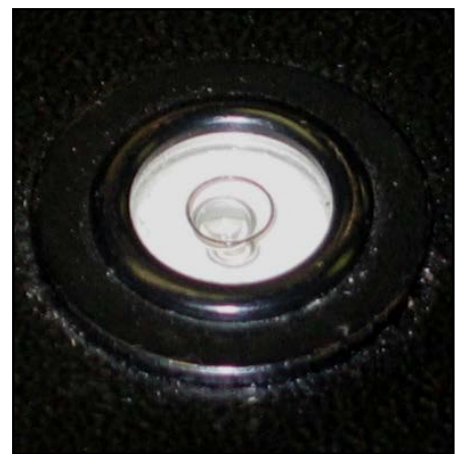

Figure 2-8. A Level Indicating Means Showing an In-level Condition.

\subsubsection{Position of Equipment}

[Code Reference: NIST Handbook 44, Section 1.10. General Code, G-UR.3.3., Section 5.56(a) UR.3.7]

a. A device or system equipped with a primary indicating element and used in direct sales, except for prescription scales, shall be positioned so that its indications may be accurately read and the weighing or measuring operation may be observed from some reasonable "customer" and "operator" position. The permissible distance between the equipment and a reasonable customer and operator position shall be determined in each case upon the basis of the individual circumstances, particularly the size and character of the indicating element....G-UR.3.3., UR.3.7.

\section{Guidance:}

When grain is traded, grain samples are taken from truckloads of grain to determine its moisture content along with other dockage factors. Moisture testing is typically performed in a separate location. At this location verify that a customer is able to read the indications of the moisture meter and observe the measurement process. Also see Section 5.3.2. "Interchange or Reversal of Parts” below or NIST Handbook 44, Section 5.56.(a), S.1.1.(b) for minimum height requirements of the digits used to display moisture content.

\subsubsection{Location and Access}

[Code Reference: NIST Handbook 44, Section 1.10. General Code, G-UR.2.3.]

a. A device shall be located, or such facilities for normal access thereto shall be provided to permit:

1. the inspecting and testing of the device;

2. the inspecting and applying security seals to the device; and 
3. readily bringing the testing equipment of the weights and measures official to the device by customary means and in the amount and size deemed necessary by such official for the proper conduct of the test.

b. Otherwise, it shall be the responsibility of the device owner or operator to supply such special facilities, including such labor as may be needed to inspect, test, and seal the device, and to transport the testing equipment to and from the device, as required by the weights and measures official. G-UR.2.3.

\section{Guidance:}

$\square \quad$ Grain moisture meters may be located in areas where it would be difficult to transport the official grain samples and other equipment necessary for testing. In these instances, the device owner must provide access for the inspector and his or her equipment so that testing can be performed.

\subsubsection{Assistance}

[Code Reference: NIST Handbook 44, Section 1.10. General Code, G-UR.4.4.]

If the design, construction, or location of any device is such as to require a testing procedure involving special equipment or accessories or an abnormal amount of labor, such equipment, accessories, and labor shall be supplied by the owner or operator of the device as required by the weights and measures official...........................................................................................UR.4.4.

\section{Guidance:}

If the design, construction, or location of a grain moisture meter requires special equipment to test the device, the device owner is responsible for providing the equipment needed to test the meter. For example, if the meter is located in a locked room, the device owner or operator must unlock the location or provide the inspector with keys to the room where the moisture meter is located. Likewise, if transporting the official samples requires an abnormal amount of labor or pose significant difficulty, the inspector can require assistance in transporting the equipment needed for the inspection.

\subsubsection{Use and Maintenance}

[Code Reference: NIST Handbook 44, Section 1.10. General Code, G-UR.4.1., G-UR.4.2., G-UR.4. and Section 5.56.(a) GMM, UR.3.1.]

a. All equipment in service and all mechanisms and devices attached thereto or used in connection therewith shall be continuously maintained in proper operating condition throughout the period of such service. Equipment in service at a single place of business shall not be considered "maintained in a proper operating condition" if found to be in error predominantly in a direction favorable to the device user; or predominantly, equipment of the same type or application is found to be in error in a direction favorable to the device user. G-UR.4.1.

b. Unstable indications or other abnormal equipment performance observed during operation shall be corrected and, if necessary, brought to the attention of competent service personnel. G-UR.4.2. 
c. Weighing elements and measuring elements that are adjustable shall be adjusted only to correct those conditions that such elements are designed to control and shall not be adjusted to compensate for defective or abnormal installation or accessories or for badly worn or otherwise defective parts of the assembly. Any faulty installation conditions shall be corrected, and any defective parts shall be renewed or suitably repaired, before adjustments are undertaken. Whenever equipment is adjusted, the adjustments shall be so made as to bring performance errors as close as practicable to zero value. G-UR.4.3

\section{Guidance:}

All equipment must be maintained in proper operating condition.

Since calibrations for all NTEP meters are based on a national sample set and/or a uniform algorithm, the issue of setting equipment predominately favorable to the device owner may be more difficult to identify for grain moisture meters than for other devices such as retail motor fuel dispensers. However, if more than one type of meter is available, these meters should not be used to take advantage of the individual meter accuracy, such as buying grain on one type of meter where the accuracy of the meter is in favor of the device owner and selling grain on another meter type that would also benefit the device owner.

Adjustment shall not be made to compensate for malfunctions of the meter. These malfunctions and faulty operations such as inappropriate blinking of indications that may cause difficulty in obtaining a measurement or cause inaccurate reading must be corrected. Also any defective parts must be replaced.

\subsubsection{Determination of Quantity and Temperature}

a. The moisture meter system shall not require the operator to judge the precise volume or weight and temperature needed to make an accurate moisture determination. External grinding, weighing, and temperature measurement operations are not permitted. In addition, if the meter is capable of measuring test weight per bushel, determination of sample volume and weight for this measurement shall be fully automatic and means shall be provided to ensure that measurements of test weight per volume are not allowed to be displayed or printed when an insufficient sample volume is available to provide an accurate measurement. S.2.6.

[Nonretroactive as of January 1, 2004]

\section{Guidance:}

$\square$ Some non-NTEP GMM moisture meters require a specific weight of grain and/or external temperature measurements (to apply a temperature correction) to determine the moisture content of grain. In order to eliminate some of the potential user errors associated with making these external measurements or grinding a grain, NTEP moisture meters must make these measurements automatically if they are needed. Verify that the meter does not require external measurements of temperature or weight or require the use of correction charts or tables to obtain a moisture measurement. 


\subsubsection{Operating Instructions}

a. Operating instructions are readily available to the user, service technician, and weights and measures official to include a list of accessory equipment and the kinds of grain or seed to be measured with the moisture meter. UR.3.1.

\section{Guidance:}

$\square$ Some jurisdictions prepare a notebook which includes operating instructions along with the grains traded on meters in their jurisdiction. Although some jurisdictions may distribute this information, device owners are responsible for making information about their specific meters available to the inspector.

\subsection{Indicating and Recording Elements}

"Indicating and Recording Elements" refer to those NIST Handbook 44 code requirements that address requirements for how a grain moisture meter shall indicate and record the measurement results. It also includes the minimum abbreviations for the identification of the grain types on a moisture meter.

\subsubsection{General}

[Code References: NIST Handbook 44, Section 1.10. General Code, G.S.5.1.]

All weighing and measuring devices shall be provided with indicating or recording elements appropriate in design and adequate in amount. Primary indications and recorded representations shall be clear, definite, accurate, and easily read under any conditions of normal operation of the device.......G-S.5.1.

\section{Guidance:}

The indications and recorded information on or from a grain moisture meter include the grain type, the percent moisture, weight per bushel, and the constituent label (moisture, protein, etc.) as appropriate, and may include other transaction information. This information must be clear, accurate, and easily read.

\subsubsection{Design}

[Code References: NIST Handbook 44, Section 5.56.(a) GMM, S.1.1.(a)-(g), S.1.2., Table S.1.2., S.1.3., S.1.5.]

a. Meters shall be equipped with a digital indicating element

b. The minimum height for the digits used to display moisture content shall be $10 \mathrm{~mm}$.

c. Meters shall be equipped with a communication interface that permits interfacing with a recording element and transmitting the date, grain type, grain moisture results, test weight per volume results, and calibration version identification.

d. A digital indicating element shall not display, and a recording element shall not record, any moisture content values or test weight per volume values before the end of the measurement cycle. 
e. Moisture content results shall be displayed and recorded as percent moisture content, wet basis. Test weight per bushel results shall be displayed and recorded as pounds per bushel. Subdivisions of these units shall be in terms of decimal subdivisions (not fractions).

f. A meter shall not display or record any moisture content or test weight per volume values when the moisture content of the grain sample is beyond the operating range of the device, unless the moisture and test weight representations include a clear error indication (and recorded error message with the recorded representation).

g. On multi-constituent meters (e.g., meters which also measure grain protein), provision shall be made for displaying and recording the constituent label (such as moisture, protein, etc.) to make it clear which constituent is associated with each of the displayed and recorded values.

\subsubsection{Selecting or Recording Grain or seed Type and Class}

[Code References: NIST Handbook 44, Section 5.56.(a) GMM, S.1.2., Table S.1.2.]

a. Provision shall be made for selecting and recording the type and class or multiclass group (as appropriate) of grain or seed to be measured. The means to select the type and class or multi-class group of grain or seed shall be readily visible and the type and class or multi-class group of grain or seed selected shall be clearly and definitely identified. Abbreviations for grain types and multi-class groups indicated on the meter must meet the minimum acceptable abbreviations listed in Table S.1.2. "Grain Types and Multi-Class Groups Considered for Type Evaluation and Calibration and Their Minimum Acceptable Abbreviations." S.1.2.

See examples of multiclass groups in table S.1.2. 


\begin{tabular}{|c|c|c|}
\hline \multicolumn{3}{|c|}{$\begin{array}{c}\text { Table S.1.2. } \\
\text { Grain Types and Multi-Class Groups Considered for Type Evaluation and Calibration and } \\
\text { Their Minimum Acceptable Abbreviations }\end{array}$} \\
\hline Grain Type & Grain Class & Minimum Acceptable Abbreviation \\
\hline \multirow{3}{*}{ Barley } & All-Class Barley* & $B A R L E Y$ \\
\hline & Six-Rowed Barley & $S R B$ \\
\hline & Two-Rowed Barley & $T R B$ \\
\hline Corn & --- & $C O R N$ \\
\hline Grain Sorghum & --- & SORG or MILO \\
\hline Oats & --- & OATS \\
\hline \multirow{3}{*}{ Rice } & All-Class Rough Rice* & RGHRICE \\
\hline & Long Grain Rough Rice & $L G R R$ \\
\hline & Medium Grain Rough Rice & $M G R R$ \\
\hline $\begin{array}{l}\text { Small Oil Seeds } \\
\text { (under consideration) }\end{array}$ & --- & --- \\
\hline Soybeans & --- & $S O Y B$ \\
\hline Sunflower seed (Oil) & --- & SUNF \\
\hline \multirow{8}{*}{ Wheat } & All-Class Wheat* & WHEAT \\
\hline & Durum Wheat & DURW \\
\hline & Hard Red Spring Wheat & HRSW \\
\hline & Hard Red Winter Wheat & HRWW \\
\hline & Hard White Wheat & HDWW \\
\hline & Soft Red Winter Wheat & SRWW \\
\hline & Soft White Wheat & $S W W$ \\
\hline & Wheat Excluding Durum* & WHTEXDUR \\
\hline
\end{tabular}

Note: Grain Types marked with an asterisk (*) are "Multi-Class Calibrations.”

[Nonretroactive as of January 1, 1998]

\section{Guidance:}

$\square \quad$ During accuracy testing verify that the meter is in compliance with the design requirement of NIST Handbook 44, Section 5.56.(a), S.1.1 (a)-(h) or Part 2. Section 5.2.2. "Design" of this manual to include minimum height for digits, display requirements, and minimum acceptable abbreviations used to identify grains. Also print a receipt and examine it for compliance.

\subsubsection{Operating Ranges and Temperatures}

[Code References: NIST Handbook 44, Section 5.56.(a) GMM, S.1.3.(a)-(d), UR.3.10.(a)-(d)]

a. A meter shall automatically and clearly indicate when the operating range of the meter has been exceeded. The operating range shall specify the following: 
1. Temperature Range of the Meter - The temperature range over which the meter may be used and still comply with the applicable requirements shall be specified. The minimum temperature range shall be $10{ }^{\circ} \mathrm{C}$ to $30^{\circ} \mathrm{C}$. No moisture value may be displayed when the temperature range is exceeded. An appropriate message shall be displayed when the temperature of the meter is outside its specified operating range.

2. Temperature Range of each Grain or Seed -The temperature range for each grain or seed for which the meter is to be used shall be specified. The minimum temperature range for each grain shall be $0{ }^{\circ} \mathrm{C}$ to $40{ }^{\circ} \mathrm{C}$. No moisture value may be displayed when the temperature range is exceeded. An appropriate error message shall be displayed when the temperature of the grain sample exceeds the specified temperature range for the grain. S.1.3.(b)

3. Moisture Range of the Grain or Seed - The moisture range for each grain or seed for which the meter is to be used shall be specified. Moisture and test weight per bushel values may be displayed when the moisture range is exceeded if accompanied by a clear indication that the moisture range has been exceeded. S.1.3.(c)

4. Maximum Allowable Meter/Grain Temperature Difference - The maximum allowable difference in temperature between the meter and the sample for which an accurate moisture determination can be made shall be specified. The minimum temperature difference shall be $10{ }^{\circ} \mathrm{C}$. No moisture value may be displayed when the maximum allowable temperature difference is exceeded. An appropriate error message shall be displayed when the difference in temperature between the meter and the sample exceeds the specified difference.

S.1.3.(d)

\section{Guidance:}

Meter operating ranges are included on the NTEP certificates of conformance. Figure 2-9. "Meter Operating Ranges Listed on a NTEP Certificate of Conformance" shows an example of operating ranges that are listed on a grain moisture certificate of conformance. Meter operating ranges are not typically verified in the field because meters will likely be maintained within their operating ranges. If conditions exist where these ranges can be verified, a test may be performed to ensure that the meter responds with the appropriate error messages.

Operating Ranges:

Ambient Temperature Range (Environment): $10^{\circ} \mathrm{C}$ to $40^{\circ} \mathrm{C}\left(50^{\circ} \mathrm{F}\right.$ to $\left.104^{\circ} \mathrm{F}\right)$

*With Hardware/Software Modification $2{ }^{\circ} \mathrm{C}$ to $45^{\circ} \mathrm{C}\left(35.6{ }^{\circ} \mathrm{F}\right.$ to $\left.113^{\circ} \mathrm{F}\right)$

Temperature Difference (Room to Grain Temperature): $20^{\circ} \mathrm{C}\left(36^{\circ} \mathrm{F}\right)$, see comments on page 3

Grain Temperature Range: $0{ }^{\circ} \mathrm{C}$ to $40{ }^{\circ} \mathrm{C}\left(32^{\circ} \mathrm{F}\right.$ to $\left.104^{\circ} \mathrm{F}\right)$

Grain Moisture Range: Refer to pages $4-7$

Figure 2-9. Meter Operating Ranges Listed on a NTEP Certificate of Conformance 


\section{b. Posting and availability of Operating Ranges}

The operating range of the grain moisture meter shall be clearly and conspicuously posted in the place of business such that the information is readily visible from a reasonable customer position. The posted information shall include the following: UR.3.10.

1. The temperature range over which the meter can be used and, if the temperature range varies for different grains or seed, the range must be specified for each.

2. The moisture range for each grain or seed for which the meter is to be used..

3. The temperature range for each grain or seed for which the meter is to be used. UR.3.10.(c)

4. The maximum allowable difference in temperature that may exist between the meter and the sample for which an accurate moisture determination can be made. UR.3.10.(d)

5. Operating instructions are readily available to the user, service technician, and weights and measures official to include a list of accessory equipment and the kinds of grain or seed to be measured with the moisture meter. .UR.3.1.

\section{Guidance:}

The device owner is responsible for posting the correct ranges of operation for the meter. Verify that the ranges specified in NIST Handbook 44, Section 5.56(a), S.1.3.(a)-(d) or Part 2, Section 5.2.3. “Operating Ranges and Temperatures" items (a) (1-4) of this manual are posted in the place of business and visible to the customer. This information should be in close proximity to the meter so that it is readily visible to a customer observing the transaction.

\section{c. Operating Temperature}

1. Warm-up Period. When a meter is turned on it shall not display or record any usable values until the operating temperature necessary for accurate determination has been attained, or the meter shall bear a conspicuous statement adjacent to the indication stating that the meter shall be turned on for a time period specified by the manufacturer prior to use. S.1.5.(a.)

2. A meter shall meet the requirements of T.2. Tolerances when operated in the temperature range of $10^{\circ} \mathrm{C}$ to $30^{\circ} \mathrm{C}\left(50^{\circ} \mathrm{F}\right.$ to $\left.86^{\circ} \mathrm{F}\right)$ or within the range specified by the meter manufacturer.

3. If the manufacturer specifies a temperature range, the range shall be at least $20^{\circ} \mathrm{C}\left(36^{\circ} \mathrm{F}\right)$.

\section{Guidance:}

$\square \quad$ The warm-up test is not typically performed in the field since meters are usually in use and the temperatures at the test location are within the operating 
temperatures of the meter. When testing at a location where the meters have not been in use for a period of time and the temperature of the location exceeds the operating temperature of the meter, the warm-up can be tested by turning the meters on and testing the meters with grain sample to verify that usable values are not recorded or displayed until the meter reaches its operating temperature.

When testing for meter accuracy within the operating ranges for the meter, the meter must meet the tolerances as specified in NIST Handbook 44, Section 5.56.(a).

When looking at the operating ranges for the meter verify the manufactures specified temperature range is at least $20^{\circ} \mathrm{C}\left(36^{\circ} \mathrm{F}\right)$

\subsubsection{Electrical Power Supply}

[Code References: NIST Handbook 44, Section 5.56.(a) GMM, S.2.2., S.2.2.1, S.2.2.2]

a. Power Supply, Voltage and Frequency. A meter that operates using alternating current must perform within the tolerances defined in Section T.2. "Tolerances" over the line voltage range $100 \mathrm{~V}$ to $130 \mathrm{~V}$, or $200 \mathrm{~V}$ to $250 \mathrm{~V}$ rms as designed, and over the frequency range of $59.5 \mathrm{~Hz}$ to $60.5 \mathrm{~Hz}$.

Battery-operated instruments shall not indicate or record values outside the applicable tolerance limits when battery power output is excessive or deficient. S.2.2.1.

b. Power Interruption. A power interruption shall not cause an indicating or recording element to display or record any values outside the applicable tolerance limits.

\section{Guidance:}

The power supply, voltage and frequency test is not typically conducted in the field on electrically powered grain moisture meters because this test requires a source to change the voltage and frequency in the power supply. However, the power supply, voltage and frequency test may be performed on battery operated instruments if it can be determined that the battery power is in excessive or deficient and then by verifying that the meter performs in tolerance while the battery power is in this condition.

If interruptions to the power can be made that do not disrupt the normal flow of business, such as turning a room switch on and off that controls the power to a moisture meter, observations may be made to verify that this interruption does not cause an indicating or recording element to display or record any values outside the applicable tolerance limit.

\subsubsection{Units and Readability}

[Code References: NIST Handbook 44, Section 5.56.(a) GMM, S.1.4.]

The display permits moisture value determination to both $0.01 \%$ and $0.1 \%$ resolution. The $0.1 \%$ resolution is for commercial transactions; the $0.01 \%$ 
resolution is for type evaluation and calibration purposes only, not for commercial purposes. Test weight per bushel values shall be determined to the nearest 0.1 pound per bushel. S.1.4.

\section{Guidance:}

Meters are allowed to display in two different percent resolutions for moisture. The $0.01 \%$ resolution is a finer resolution to allow for rounding during type evaluation and calibration of the meter. There is a single resolution for test weight per bushel which is 0.1 pounds per bushel. The $0.1 \%$ resolution for moisture and the 0.1 pounds per bushel must be used for commercial transactions. Prior to accuracy testing, ensure that the meter is indicating in $0.1 \%$ resolution for moisture and in 0.1 pounds per bushel for test weight. If the meter is indicating in a different resolution record the "as found" resolution on your report form; explain the requirement to the device owner; and have the device owner change the resolution to the appropriate resolution for field testing following instructions in the operation manual.

\subsubsection{Recorded Representation}

[Code References: NIST Handbook 44, Section 5.56.(a) GMM, G-S.5.6., UR.3.4. (a), (b)]

a. Insofar as they are appropriate, the requirements for indicating and recording elements shall also apply to recorded representations. All recorded values shall be printed digitally. In applications where recorded representations are required, the customer may be given the option of not receiving the recorded representation. For systems equipped with the capability of issuing an electronic receipt, ticket, or other recorded representation, the customer may be given the option to receive any required information electronically (e.g., via cell phone, computer, etc.) in lieu of or in addition to a hard copy......G-S.5.6.

b. Printed tickets must be free from any previous indication of moisture content or type of grain or seed selected. The customer shall be given a printed ticket showing the date, grain type, grain moisture results, test weight per bushel, and calibration version identification. The ticket shall be generated by the grain moisture meter system. UR.3.4.(a),(b)

\section{Guidance:}

Observe transactions to ensure that a printed ticket is given to customers and the printed results show all of the information listed in NIST Handbook 44, Section 5.56.(a), UR.3.4. or in Part 2, Section 5.2.7. "Recorded Representation" of this manual. Also verify that the receipt is printed from the grain moisture meter system. This may be printed by a printer integral to the grain moisture meter or by an external printer interfaced to the meter; the receipt may not be generated by manual operation. During accuracy testing print out and review a ticket.

\subsubsection{Provisions for Sealing}

[Code References: NIST Handbook 44, Section 1.10. General Code, G-S.8., G-UR.4.5., Section 5.56.(a) GMM, S.2.5., Table S.2.5.]

a. A device shall be designed with provision(s) for applying a security seal that must be broken, or for using other approved means of providing security (e.g., 
Part 2: Field Inspection and Evaluation

data change audit trails available at the time of inspection), before any change that detrimentally affects the metrological integrity of the device can be made to any electronic mechanism. G-S.8.

[Nonretroactive as of January 1, 1990]

b. A security seal shall be appropriately affixed to any adjustment mechanism designed to be sealed. G-UR.4.5.

c. Provision shall be made for applying a security seal in a manner that requires the security seal to be broken, or for using other approved means of providing security (e.g., audit trail available at the time of inspection as defined in Table S.2.5. "Categories of Device and Methods of Sealing," NIST Handbook 44, Section 5.56.(a) before any change that affects the metrological integrity of the device can be made to any mechanism. S.2.5.

\section{Guidance:}

If a feature or parameter of the moisture meter can be changed, that will affect the measurement of a device, there must be a means for sealing that feature or parameter to ensure that there is evidence that a change was made to the device. A list of the features and parameters to be sealed are included in Publication 14. Acceptable forms of sealing are a physical seal, an event counter or an event logger. These types of sealing are applied according to the category of the device. Meters are classified as category 1, 2, 3, 3a, and 3b devices:

0 If a meter is classified as a Category 1 device, which is a meter that does not have remote configuration, the method for sealing can be a physical seal or two event counters.

0 If a meter is classified as a Category 2 device, which is a device with remote configuration but access is controlled by physical hardware, the hardware for access to remote communication must have a physical seal or two event counters.

0 If a meter is classified as a Category 3 device, which is a device with remote configuration, a Category 3a, device which is a device with no remote configuration but the operator is able to make slope and bias changes or a Category $3 b$ device, which is a device with no remote configuration but metrological changes can be made through a software switch such as a password, these categories require an event logger.

The NTEP certificate of conformance for a grain moisture meter provides information on the type of sealing associated with the meter and includes the location of a physical seal or guidelines for accessing event logger and/or event counter information. Most NTEP meters are Category 3 devices requiring an audit trail (an event logger or event counter). Figure 2-10. "Audit Trail and Key for Description of Audit Trail Changes," contains a printout of an event logger from a NTEP grain moisture meter and a key to identify the codes on the event log. During testing, review the CC to determine the type of sealing associated with the meter being tested then print and review the event logger or event counter to ensure that it meets the requirements of NIST Handbook 44, Section 5.56.(a), Table S.2.5. "Categories of Device and Methods of Sealing" or observe the physical seal to 
ensure that the seal is secure and provides adequate security. For meters with event loggers or event counters, review the printed event logger or counter for any patterns that may indicate inappropriate changes. For example, one pattern that may indicate inappropriate changes may be excessive changes during peak harvest times. Note on your inspection report whether or not physical seals are intact, note settings for any event counters, and attach a copy of the event log if applicable. 
Part 2: Field Inspection and Evaluation

Figure 2-10. Audit Trail and Key for Description of Audit Trail Changes.

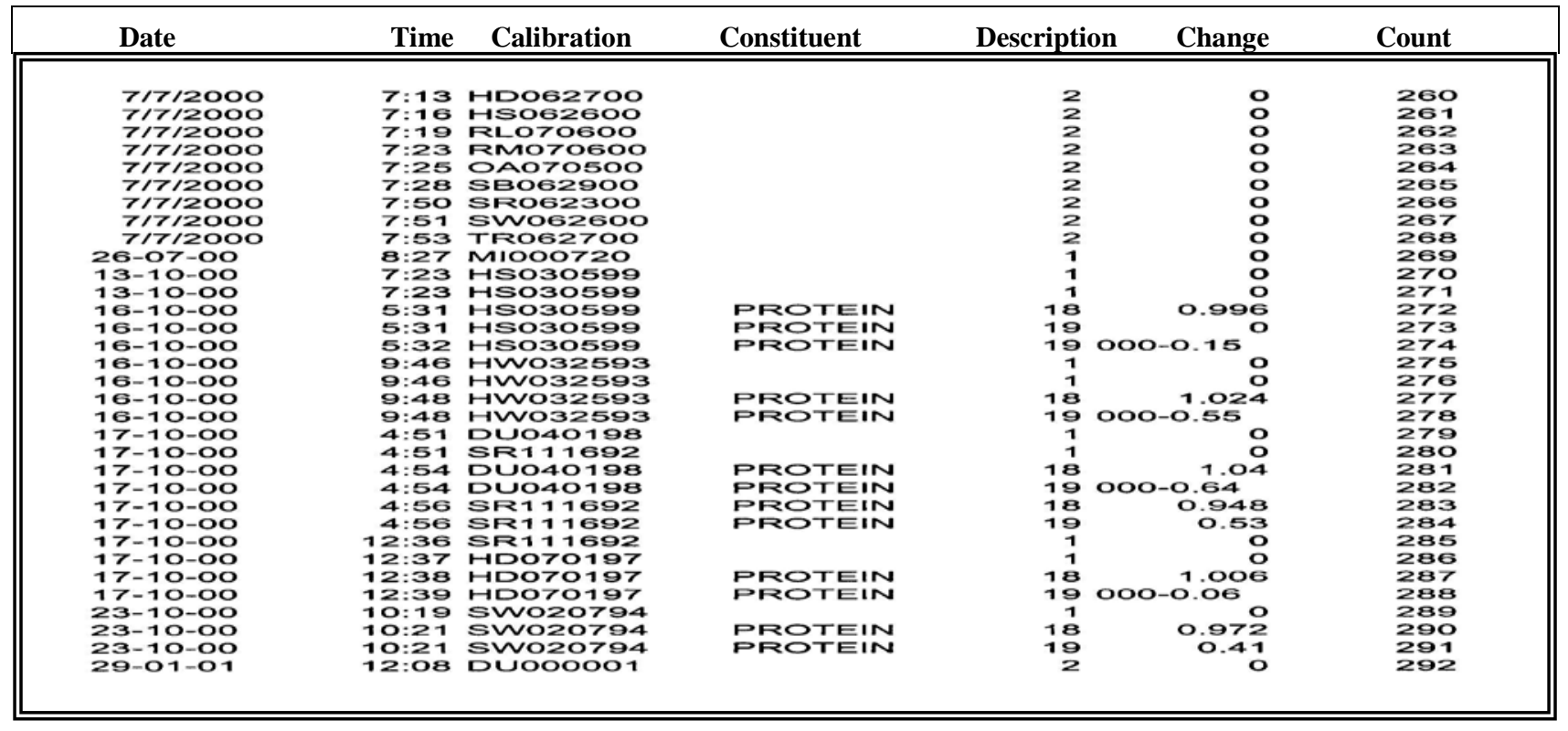

\begin{tabular}{|c|l|c|l||}
\hline ID & Description of metrological changes & ID & Description of metrological changes \\
\hline \hline 1 & Import an application model & 12 & A-constant (residual) (constituent parameter). \\
\hline 2 & Delete an application model. & 13 & B-constant(leverage) (constituent parameter). \\
\hline 3 & The date setting is changed. & 14 & Low limit (constituent parameter). \\
\hline 4 & The time setting is changed. & 15 & High limit (constituent parameter). \\
\hline 5 & The P Constant is changed & 16 & $\begin{array}{l}\text { C-constant (standard deviation (std dev)) (constituent } \\
\text { parameter). }\end{array}$ \\
\hline 6 & The O constant is changed & 17 & Number of printed decimals (constituent parameter). \\
\hline 7 & The S constant is changed & 18 & Slope changes (constituent parameter) \\
\hline 8 & The min temperature is changed (constituent parameter) & 19 & Changes of BIAS (constituent parameter). \\
\hline 9 & The max temperature is changed (constituent parameter) & 20 & Moisture correction (constituent parameter). \\
\hline 10 & Instrument temperature limit. & 21 & Correction of constituent (constituent parameter). \\
\hline 11 & Number of subsamples (application model parameter). & 22 & Make correction (constituent parameter). \\
\hline
\end{tabular}

\subsection{Marking Requirements}

Marking requirements specify what must be marked on the grain moisture meter for proper identification of the device and marking requirements for operational controls; graduations; indications; and features.

\subsubsection{General Identification}

[Code Reference: NIST Handbook 44, Section 1.10. General Code, G-S.1.(a)-(e)]

a. All equipment, except weights and separate parts necessary to the measurement process but not having any metrological effect, shall be clearly 
and permanently marked for purposes of identification with the following information: G-S.1.(a)-(e)

1. the name, initials, or trademark of the manufacturer or distributor;...G-S.1.(a)

2. a model identifier that positively identifies the pattern or design of the device;

- $\quad$ The model identifier shall be prefaced by the word "Model," "Type," or "Pattern." These terms may be followed by the word "Number" or an abbreviation of that word. The abbreviation for the word "Number" shall, as a minimum, begin with the letter "N" (e.g., No or No.). The abbreviation for the word "Model" shall be "Mod" or "Mod." Prefix lettering may be initial capitals, all capitals, or all lower case.

[Nonretroactive as of January 1, 2003]

(Added 2000) (Amended 2001)

3. a nonrepetitive serial number, except for equipment with no moving or electronic component parts and not-built-for-purpose, software-based devices; G-S.1.(c)

[Nonretroactive as of January 1, 1968]

(Amended 2003)

- $\quad$ The serial number shall be prefaced by words, an abbreviation, or a symbol, that clearly identifies the number as the required serial number.

[Nonretroactive as of January 1, 1986]

- Abbreviations for the word "Serial" shall, as a minimum, begin with the letter "S," and abbreviations for the word "Number" shall, as a minimum, begin with the letter " $N$ " (e.g., S/N, SN, Ser. No., and S. No.).

[Nonretroactive as of January 1, 2001]

4. the current software version or revision identifier for not-built-for-purpose, software-based devices; .G-S.1.(d)

[Nonretroactive as of January 1, 2004]

(Added 2003)

- The version or revision identifier shall be prefaced by words, an abbreviation, or a symbol, that clearly identifies the number as the required version or revision.

[Nonretroactive as of January 1, 2007]

(Added 2006)

- Abbreviations for the word "Version" shall, as a minimum, begin with the letter " $V$ " and may be followed by the word "Number." Abbreviations for the word "Revision" shall, as a minimum, begin with the letter " $R$ " and may be followed by the word "Number." The 
abbreviation for the word "Number" shall, as a minimum, begin with the letter " $N$ " (e.g., No or No.).

[Nonretroactive as of January 1, 2007]

(Added 2006)

5. a National Type Evaluation Program (NTEP) Certificate of Conformance (CC) number or a corresponding CC Addendum Number for devices that have a CC. The CC Number or a corresponding CC Addendum Number shall be prefaced by the terms "NTEP CC," "CC," or "Approval." These terms may be followed by the word "Number" or an abbreviation of that word. The abbreviation for the word "Number" shall, as a minimum, begin with the letter " $N$ " (e.g., No or No.). G-S.1.(e) [Nonretroactive as of January 1, 2003]

\section{Guidance:}

$\square \quad$ Meters must be marked in accordance with NIST Handbook 44, Section 1.10. General Code, G.S.1.(a)-(e). Much of the marking information required by GS.1. is often found on an identification badge. However, the information is not required to be marked on a badge and may be located at various places on the device, provided it complies with visibility and permanence requirements. Devices must be marked with the appropriate information to ensure that each device is uniquely identified so that proper records and inspection trails can be maintained by weights and measures jurisdictions and service agencies. Appropriate markings are also necessary to track devices that may have been sold or transferred to different business locations in or out of jurisdictions. Prior to testing locate the identification information on the meter. Confirm that identification of the meter includes all the requirements included in NIST Handbook 44, Section 1.10. General Code, G.S.1.(a)-(e) and record the necessary information on the test report. Figure 2-11. "Examples of pre 2003 Identification Badge” shows a sample identification badge. In this sample, the ID badge does not include a CC number. Although this ID badge does not include a CC number, it meets the requirements of NIST Handbook 44 because it was manufactured prior to January 1,2003 . The requirement for including a CC number only applies to meters manufactured after January 1, 2003. The NTEP CC includes information on where to locate the identification badge and identification information that can be assessed from the instrument display.

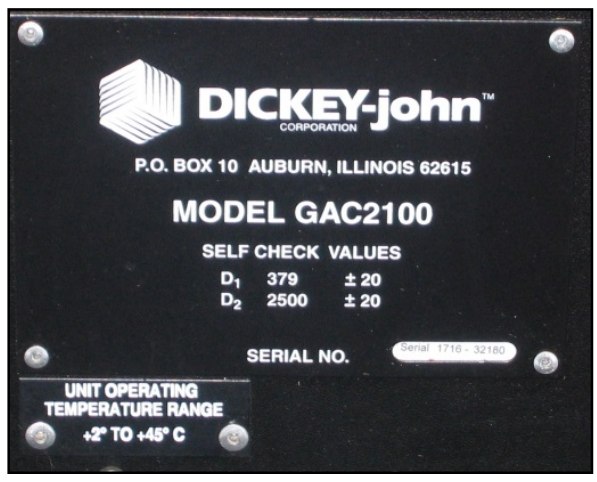

Figure 2-11. Example of pre 2003 Identification Badge. (Note: The ID badge does not include a CC number.) 


\subsubsection{Interchange or Reversal of Parts}

a. Parts of a device that may readily be interchanged or reversed in the course of field assembly or of normal usage shall be: G-S.4.(a),G-S.4.(b)

1. so constructed that their interchange or reversal will not affect the performance of the device; or

2. so marked as to show their proper positions.

\section{Guidance:}

$\square$ During an inspection of any new meter designs with interchangeable or reversible parts, testing should be performed to ensure that these parts are marked appropriately and if not marked they do not affect the performance. If the part is not properly marked to show its proper position, a test can be performed by first testing the meter with the part attached in one direction then reattaching the part in another direction to determine if the reversal of the part affected the performance of the device. This is to ensure that reversing a part does not cause inaccurate measurements. Current designs of NTEP grain moisture meters do not have parts that can be readily interchanged during normal use. As with other Handbook 44 requirements, compliance with these requirements is verified during type evaluation.

\subsubsection{Marking, Operational Controls, Indications and Features}

a. All operational controls, indications, and features, including switches, lights, displays, push buttons, and other means, shall be clearly and definitely identified. The use of approved pictograms or symbols shall be acceptable.

[Nonretroactive as of January 1, 1977] .G-S.6.

\section{Guidance:}

$\square \quad$ Review the identification of operational controls, indications, switches, light displays, and push buttons to ensure that they are clearly identified. These requirements help to ensure that device owners can operate the device appropriately and ensures consumers can understand the transaction and information displayed and recorded. This identification may include pictograms or symbols that have been approved by the weights and measures community and that would be readily understood by an operator or consumer. Information on identification of the operational controls is typically located in the manufacturer's operations manual. Figure 2-12. "Identified Operational Controls" below shows the identification of operational controls on one NTEP meter. 


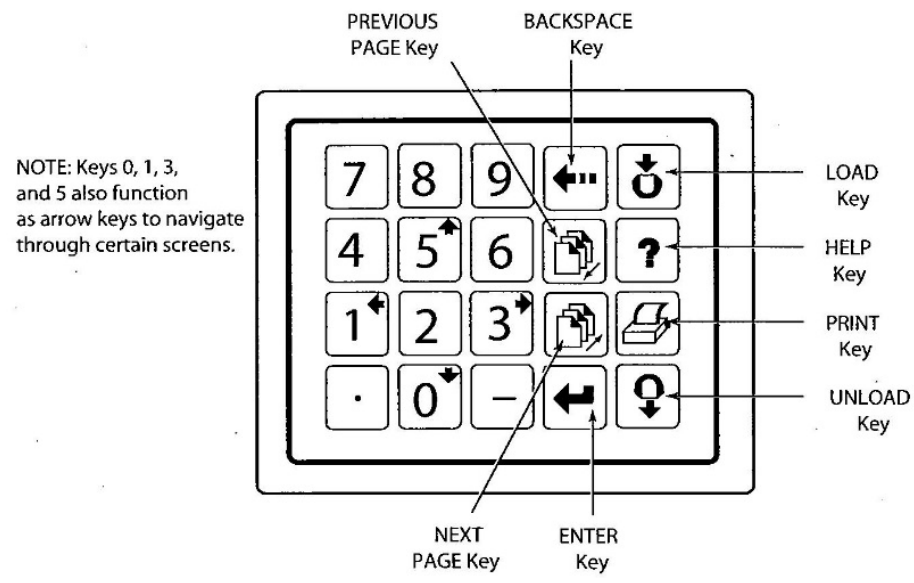

Figure 2-12. Identified Operational Controls.

\subsubsection{Values}

If graduations, indications, or recorded representations are intended to have specific values, these shall be adequately defined by a sufficient number of figures, words, symbols, or combinations thereof, uniformly placed with reference to the graduations, indications, or recorded representations and as close thereto as practicable, but not so positioned as to interfere with the accuracy of reading. G-S.5.2.4.

\section{Guidance:}

$\square \quad$ Grain moisture meters and multi-constituent meters measure moisture and/or protein, starch, and oil of grains in percent (\%) value and grain test weight in pound per bushel (lb/bu) or Kilogram per hectoliter $(\mathrm{kg} / \mathrm{hl})$. Abbreviations for grain type may also be used in accordance with NIST Handbook 44, Section 5.56.(a), Table S.1.2. "Grain Types and Multi-Class Groups Considered for Type Evaluation and Calibration and Their Minimum Acceptable Abbreviations." Observations should be made while testing to ensure that the constituents are properly labeled; that minimum acceptable abbreviations are used for the various grain types; and that the measurement values are identified appropriately.

\subsubsection{Permanence}

Graduations, indications, or recorded representations and their defining figures, words, and symbols shall be of such character that they will not tend easily to become obliterated or illegible. G-S.5.2.5.

\subsubsection{On Devices that Indicate or Record in more than One Unit}

On devices designed to indicate or record in more than one unit of measurement, the values indicated and recorded shall be identified with an appropriate word, symbol, or abbreviation. G-S.5.3.1.

\subsubsection{Lettering}

All required markings and instructions shall be distinct and easily readable and shall be of such character that they will not tend to become obliterated or illegible. ..G-S.7. 


\subsubsection{Other Devices not used for Commercial Measurements}

If there are other moisture meters on the premises not used for trade or determining other charges for services, these devices shall be clearly and conspicuously marked "Not for Use in Trade or Commerce." .UR.3.2

\section{Guidance:}

$\square \quad$ Examine the markings on all meters on the premises. For those not used commercially ensure that they are marked "Not for Use in Trade. For all others observe that:

o symbols, words and figures are not easily obliterated;

o different units are properly identified; and

o marking and instruction are easily read.

\subsection{Measuring Element}

\subsubsection{Accessory Devices/Equipment}

When the operating instructions for a moisture meter require accessory equipment separate from and external to the moisture meter, such equipment shall be appropriate and complete for the measurement and Accessory devices, if necessary in the determination of a moisture content value, shall be in close proximity to the moisture meter and allow immediate use. S.3., UR.3.5.

\subsubsection{Current Calibration Data}

a. Grain moisture determinations must be made using only the most recently published calibration data. UR.3.9.

b. A meter must be capable of displaying either calibration constants, a unique calibration name, or a unique calibration version number for use in verifying that the latest version of the calibration is being used to make moisture content and test weight per bushel determinations. S.2.4.1.

\section{Guidance:}

$\square \quad$ Grain moisture meter calibrations are based on how the meter reacts to grain samples, which vary with each crop year. As such, the calibrations of grain moisture meter may change on an annual basis. Meter manufacturers provide meter owners with the most current calibrations annually. Device owners are responsible for ensuring that the latest calibrations are installed on the meter. Calibration constants, unique calibration name, or calibration versions numbers for grain moisture meters are listed on the NTEP CC. An example of the calibrations and calibration version number on a CC are shown in Figure 2-13. "Calibrations Data from a GMM Certificate of Conformance." Compare the meter calibrations, unique calibration name or calibration version on the meter to the values on the most current CC to verify that the most recent calibrations are installed on the meter. 
Part 2: Field Inspection and Evaluation

\begin{tabular}{l}
\hline Hard Red Winter Wheat \\
Designation: Wheat HRW \\
Calibration Version: 060308n \\
Moisture Range - Approved: $6 \%-20 \%$ \\
Moisture Range - Pending: $6 \%-22 \%$ \\
Calibration Constants: \\
K1 = $0673 \mathrm{~K} 4=0738 \mathrm{~K} 7=2206$ \\
$\mathrm{~K} 2=1716 \mathrm{~K} 5=2500 \mathrm{~K} 8=9948$ \\
$\mathrm{~K} 3=1247 \mathrm{~K} 6=1074 \mathrm{~K} 9=1045$ \\
Test Weight per bushel: Approved \\
\hline
\end{tabular}

Figure 2-13. Calibration Data from a GMM Certificate of Conformance.

\section{Pretest Determinations}

\subsection{Grains and Constituents}

Determine the kind of grains, and constituents the device is used to measure and select the grains for use in inspecting and testing the meter.

\subsection{Tolerances}

[Code References: NIST Handbook 44, Section 5.56.(a) GMM, T.1., T.2., T.3.]

\subsubsection{How to Apply Tolerances}

a. Tolerances shall be applied to the average of at least three measurements on each official grain sample for moisture and weight per bushel measurements)

b. The tolerances hereinafter prescribed shall be applied to errors of underregistration and errors of overregistration. T.1.

c. Air Oven Reference Method. - Maintenance and acceptance tolerances shall be as shown in Table T.2.1. "Acceptance and Maintenance Tolerances AirOven Reference Method.” Tolerances are expressed as a fraction of the percent moisture content of the official grain sample, together with a minimum tolerance. T.2., T.2.1. 


\begin{tabular}{||c|c|c||}
\hline \multicolumn{3}{|c|}{ Table T.2.1. } \\
Acceptance and Maintenance Tolerances Air-Oven Reference Methods \\
\hline \hline Type of Grain, Class, or Seed & Tolerance & Minimum Tolerance \\
\hline $\begin{array}{c}\text { Corn, oats, rice, sorghum, } \\
\text { sunflowers }\end{array}$ & $\begin{array}{c}0.05 \text { of the percent } \\
\text { moisture content }\end{array}$ & $\begin{array}{c}0.8 \% \\
\text { in moisture content }\end{array}$ \\
\hline $\begin{array}{c}\text { All other cereal grains an doil } \\
\text { seeds }\end{array}$ & $\begin{array}{c}0.04 \text { of the percent } \\
\text { moisture content }\end{array}$ & $\begin{array}{c}0.7 \% \\
\text { in moisture content }\end{array}$ \\
\hline
\end{tabular}

(Amended 2001)

d. The maintenance and acceptance tolerances on test weight per bushel indications or recorded representations are shown in Table T.3. "Acceptance and Maintenance Tolerances Test Weight per Bushel.” T.3.

\begin{tabular}{|c|c|}
\hline \multicolumn{2}{|c|}{$\begin{array}{l}\text { Table T.3. } \\
\text { Acceptance and Maintenance Tolerances Test Weight per Bushel }\end{array}$} \\
\hline Type of Grain or Seed & $\begin{array}{c}\text { Tolerance } \\
\text { (Pounds Per Bushel) }\end{array}$ \\
\hline Corn, oats & 0.8 \\
\hline All wheat classes & 0.5 \\
\hline $\begin{array}{l}\text { Soybeans, all barley classes, all rice } \\
\text { classes, sunflower, sorghum }\end{array}$ & 0.7 \\
\hline
\end{tabular}

(Added 2003)

\section{Guidance:}

$\square \quad$ The following is an example of calculating the tolerance for a wheat sample:

Per Table T.2.1. "Acceptance and Maintenance Tolerances Air-Oven Reference Methods," the tolerance for wheat is 0.04 of the percent moisture content of the standard grain sample, with a minimum tolerance of $\pm 0.7 \%$. If the wheat sample moisture is $16 \%$, the tolerance is calculated by multiplying the tolerance by the percent moisture:

$$
\pm 0.04 \times 16 \%=0.64 \%
$$

So the tolerance to be applied to this test is $\pm 0.64 \%$. However, since the minimum tolerance to be applied is $\pm 0.7 \%$, the tolerance for the test is $\pm 0.7 \%$.

$\square$ The tolerances for test weight measurements are applied directly to the measurement. The sample used for test weight has a test weight value assigned by the laboratory. The sample is placed in the meter and the test weight indicated by the meter is compared to the laboratory assigned test weight values of the sample. 


\section{Test Notes}

\subsection{Official Grain Sample Maintenance, Test Methods and Documentation}

The moisture of official grain samples will change over time due to temperature, environmental conditions, and stability of the grain samples. To maximize the use of the official grain example and ensure that the moisture value of the sample is maintained throughout testing, field inspectors must follow guidelines and test procedures included in this section. The test methods and documentation needed to perform inspection and testing are also included in this section.

\subsubsection{Storage}

Official grain samples received from the laboratory are to be stored in a refrigerator and maintained at $2{ }^{\circ} \mathrm{C}\left(35^{\circ} \mathrm{F}\right)$ to $4{ }^{\circ} \mathrm{C}\left(40^{\circ} \mathrm{F}\right)$ until needed.

\subsubsection{Official Grain Samples used for Field Testing}

Official grain samples for field testing are grains that are representative of the grain types and moisture ranges normally traded in a jurisdiction. Three or more official grain samples with a high moisture content and three or more official grain samples with a low moisture content for each grain type are used for field testing commercial grain moisture meters. One of the three or more official grain samples is retained as a backup for each grain type and moisture. Each of the remaining samples is used as an official sample until it has been dropped for the number of times described in Part 2, Section 7.1.4. "Minimum Test and Maximum Number of Drops” of this manual.

\subsubsection{Warming Official Grain Samples in Preparation for Testing}

Approximately two hours before use (consider travel time in this two-hour period), remove only the official grain standards from the refrigerator that will be used for moisture meter field evaluation for that day of testing and shake the sample several times (for homogeneity). Place the samples in a transport cooler WITHOUT ICE. This will allow the grain sample to stabilize to ambient temperature and minimize exposure to temperature extremes and fluctuations. The sample jars or bags should be spread out to allow the air to move freely about them. Official grain samples which are being used to test moisture meters for the current day should be stored in the transport cooler when not in use. If there are significant down times between tests during the day, grain standards should be stored in the refrigerator until two hours before they are needed. Backup samples must remain in the portable refrigerator until needed by the inspector. When it is determined that the back-up sample is needed that day, the back-up sample should be placed in the cooler along with the day's primary samples.

Note: Throughout the handling period when the grain is not refrigerated, occasionally shake each grain sample to mix the grain several times and also be sure to shake the grain sample before removing the sealing lid for any purpose.

\subsubsection{Minimum Test and Maximum Number of Drops}

a. A minimum test of a grain moisture meter consists of testing the moisture and if applicable, test weight meter measurements. 
b. When testing for moisture, the meter is to be tested using official grain samples having at least two different moisture content values ("high" and "low" moisture content) within the operating range of the device and representing the "high" and "low" moisture values at which a specific grain is traded within a jurisdiction.

c. When applicable, the test weight feature on the meter should be tested using an official grain sample with the lowest moisture value.

d. The moisture value of grain samples may begin to change in moisture during meter testing. High moisture corn and soybeans and other grains and moistures have a maximum number of drops during testing. High moisture corn and soybeans and rough rice standard samples can be used for a maximum number of 18 drops. Corn and soybeans below $18 \%$ and all other grains and moistures have a maximum number of 24 drops. Extended use of grains for more than the specified maximum number of drops must be supported by data to show that testing is not affected by the extended use of the grain samples.

\subsubsection{Preparation of the Official Grain Samples upon Arrival at the Test Site}

a. Upon arrival at the test site, transport the official grain samples to the meter location in the transport cooler. The grain samples should be taken into the room where the moisture meter is located; taken out of the transport cooler; and placed near the moisture meter to allow them to reach the temperature of the room before the jar is opened. Jars should not be opened until the grain is within 10 degrees of the room temperature. Moisture will condense on the grain if a cold grain standard is opened before its temperature stabilizes. Except when inserting a thermometer to take the temperature of the grain, the jar containing the official grain sample is never opened without first allowing the grain to stabilize and is only exposed while conducting the moisture meter test.

b. Take the temperature of the grain sample with the least amount of exposure to the environment. One method is to quickly replace the lid on the sample with a rubber stopper or lid with a hole that allows a thermometer to be inserted into the sample.

c. In order to ensure a valid result, care must be taken so that the moisture values of the samples are carefully maintained. High moisture samples are more susceptible to moisture loss and spoilage; therefore, it is recommended that the inspection begin with the sample having the highest moisture value and proceed to the samples with the lower moisture values to limit the amount of time that the high moisture samples are exposed to ambient conditions.

d. Work with only one sample at a time to avoid the possibility of confusing/mixing the samples.

e. Carefully monitor each sample in order to detect any erratic meter readings or foul odor which could indicate sample deterioration.

f. To avoid contamination of the official samples, the meter, its parts, and accessory equipment must be clear of other grain before using the official grain samples in the meter. Prior to using an official grain sample in a GMM under 
test, check to ensure that the GMM dump cells, filling hoppers, grain drawers (receiving trays), etc. are clean and there is no buildup of residue.

g. Before opening the sample to begin testing the GMM, review all the details of the inspection so that handling of the grain and the time the sample is out of the sealed container can be minimized.

h. Field inspectors are responsible for refrigerating samples at the end of each day and for keeping samples in a cooler or refrigerator between inspection points. Inspectors are also responsible for monitoring sample conditions and possible moisture changes to determine when replacement is necessary. This includes keeping the sample free of contamination from other grains, souring or molding grain, and insects, all of which may cause erratic readings. A primary grain sample that begins to fail on all meters may be indicative of a moisture change in the primary grain sample. If a primary sample is compromised as noted above, the back-up sample should be used to confirm the readings. If meters pass with the back-up sample, place the previously used official grain sample in the refrigerator for return to the laboratory, and use the back-up grain sample to complete the testing.

\subsubsection{Field Inspection and Test Method}

Field inspection of NTEP grain moisture meters or meters manufactured or placed into service after January 1, 1998, must be conducted in accordance with NIST Handbook 44, Section 5.56.(a). This manual provides guidelines for using the air-oven reference method transfer standards to test GMM and multiconstituent grain analyzers that measure moisture in accordance with NIST Handbook 44, Section 5.56.(a), N.1.1.

\subsubsection{Documentation}

In addition to NIST Handbook 44, other documents are needed and useful in performing the inspection of GMMs. These documents provide information on jurisdictional policy, device operation, accessing audit trail information, verifying NTEP identification information, and the location of businesses with grain moisture meters.

\section{a. Departmental Policy and Inspection Procedures}

Many weights and measures jurisdictions have state and/or local policies and inspection procedures that are followed during an inspection. These procedures should be provided to the inspector for reference.

b. Moisture Meter Operating Instructions and Current Certificates of Conformance (CC) for Moisture Meters

GMM operating instructions from the manufacturer will provide the inspector with detailed information on how to operate the meter and will be useful to the inspector if the meter is new or if it is the first time an inspector has tested a specific type of meter. CCs are available for all NTEP GMMs and may be obtained from the NCWM, Inc. website at www.ncwm.net. A CC for grain moisture meters includes the most current calibration constants, sealing requirements, and other useful information that the inspector will need to perform an inspection. 


\section{c. List of Moisture Meters and Locations, Type of Meters(s), and Types(s)} of Grain Purchased

Many weights and measures jurisdictions maintain a database or other listing of moisture meters with the location, type of meters, and grains purchased. This information will be helpful for the inspectors to prepare for testing.

\subsection{Official Grain Samples (Transfer Standards), Minimum Test, Minimum Sample Size.}

[Code References: NIST Handbook 44, Section 5.56.(a) GMM, N.1.1., N.1.2., UR.3.3., S.2.1.]

a. Official grain samples shall be used as the official transfer standards with moisture content and test weight per bushel values assigned by the reference methods. The reference methods for moisture shall be the oven drying methods as specified by the USDA GIPSA. The test weight per bushel value assigned to a test weight transfer standard shall be the average of 10 test weight per bushel determinations using the quart kettle test weight per bushel apparatus as specified by the USDA GIPSA. Tolerances shall be applied to the average of at least three measurements on each official grain sample. Official grain samples shall be clean and naturally moist, but not tempered (i.e., water not added). N.1.1.

b. A means to prevent condensation of moisture or loss of moisture from grain samples must be used. For example, a cold grain sample should be kept in a closed container in order to permit the cold grain to come to within the operating temperature range of the meter before the grain moisture measurements are made. ..UR.3.3.

c. Meters shall be designed to measure the moisture content of representative-size grain samples. The minimum allowable sample size used in analysis shall be $100 \mathrm{~g}$ or 400 kernels or seeds, whichever is smaller.

d. A minimum test of a grain moisture meter consists of test with samples (need not exceed three) of each grain or seed for which the device is used and for each grain or seed type shall include the following: N.1.2.

- $\quad$ tests of moisture indications, using samples having at least two different moisture content values within the operating range of the device.

- if applicable, tests of test weight per bushel indications with at least the lowest moisture samples used in (a) above. 


\section{Safety Reminders}

\section{Lifting.}

- Be familiar with and use proper lifting techniques when lifting grain samples or heavy equipment to prevent personal injury.

o To reduce the possibility of back injury, use equipment which would decrease the amount of lifting required whenever possible (e.g., an extended height funnel, or carts for transporting grain samples)

o Periodic training in proper lifting techniques is encouraged.

\section{Grain Sample Container.}

- Use a lid opener if a grain sample container lid is too tight to be removed comfortably by hand. Do not strain. When opening samples, grasp the containers firmly with good hand and wrist positioning and grip.

- Dry condensation from the outside of a grain sample container to prevent slippage and possible breakage of container and/or injury to feet.

- Watch for chips, cracks, or breakage of glass containers. If found, dispose of the container properly to prevent injury to the inspector or damage to the GMM. A damaged container may also affect the integrity of the grain sample moisture.

\section{Test}

\subsection{Minimum Test}

Carefully review Section 7.1. "Official Grain Sample Maintenance, Test Methods and Documentation," before beginning the minimum test procedures and follow the guidelines in this section.

a. Determine the official grain sample temperature and the ambient temperature. Do not remove the grain from the container until the grain is within $10^{\circ} \mathrm{F}$ of the ambient temperature.

b. When the grain comes to within the desired temperature, pour the entire contents of the official grain sample into a larger, clean glass container. Rotate the container about 10 times to further homogenize the contents and equilibrate the temperature.

c. Following the GMM operating instructions, select the grain type to be tested on the GMM.

d. Fill the grain hopper with the official grain sample, starting with the high moisture sample first.

e. Following the GMM operating instructions drop the official grain sample through the meter and record the moisture results. Repeat the test for a total of three measurements. 
f. If there are other GMMs at the inspection site, repeat steps (a.) through (e.) with the same official grain sample, working in assembly-line fashion as quickly as possible.

g. Return the official grain sample to its original, clean jar; seal the jar with its lid; mark the jar with the number of drops; and return the jar to the cooler.

h. Analyze the test results by averaging the three-meter moisture measurements for each meter and comparing the average meter moisture to the known moisture value of the official grain sample and record the error.

i. If the meter is not in tolerance and you suspect that the sample has changed, is damaged, or contaminated, repeat steps (a.) through (h.) with the back-up sample. If the results from the back-up sample agree with the results from the primary sample, record the results; return the back-up sample to the cooler; and continue to use the primary sample as the standard.

j. $\quad$ Proceed to the next lower moisture level of that grain and repeat steps (a.) through (h.)

k. If the results from the back-up sample are different, return the primary sample to the portable refrigerator for return to the laboratory. Use the back-up sample as the primary from this point.

l. Repeat steps (a.) through (h.) for each grain and each moisture level.

m. If appropriate, test the test weight per volume (e.g., test weight per bushel) indications with at least the lowest moisture sample. Drop the official grain sample with the lowest moisture through the meter three times and record the results. Analyze the test results by averaging the three-meter test weight measurements for each meter and comparing the average meter test weight to the known test weight value of the official grain sample and record the error. Evaluation of the test weight per bushel indications can be performed while testing the moisture indications or a weights and measures jurisdiction may choose to use a separate, low-moisture sample to test the accuracy of the test weight indications.

n. Remember to mark each sample label with the number of times that sample is dropped and the number of times that sample was warmed.

o. Verify that the seals of the jars are tight and return the samples to the portable refrigerator as soon as testing is completed for the day.

p. When samples exceed a specified number of drops, 18 drops for corn and soybeans above $18 \%$ or 24 drops for all other grain types, the sample must be returned to the laboratory and retested. A jurisdiction may determine that the maximum number of drops can be increased with supporting historical data. 


\section{Post Test Tasks}

\subsection{Provisions for Sealing}

[Code References: NIST Handbook 44, Section 5.56.(a) GMM, S.2.5.]

Provision shall be made for applying a security seal in a manner that requires the security seal to be broken, or for using other approved means of providing security (e.g., audit trail available at the time of inspection as defined in Table S.2.5. "Categories of Device and Methods of Sealing," NIST Handbook 44, Section 5.56.(a) before any change that affects the metrological integrity of the device can be made to any mechanism. S.2.5.

\section{Guidance:}

As appropriate, follow the instructions for accessing audit trail information in the NTEP certificate "Field Inspection Notes" and review the audit trail of the GMM device for compliance with NIST Handbook 44. As appropriate, check for the presence of a physical security seal on the meter. Document missing physical seals on the official report and apply new ones as needed. Attach a copy of the printed event logger or event counter to the test report and record any concerns on the test report.

\subsection{Record Results}

Record the test results on an official test report. See Appendix A for a sample test report. A test report form for grain moisture meters should contain as a minimum:

a. name or initials of person performing the evaluation;

b. date;

c. description of the device, model, and serial number;

d. environmental readings such as temperature, where applicable;

e. identification of standard grain samples (i.e., sample ID);

f. device owner, name, address and phone number;

g. device CC number;

\section{Safety Reminders}

- Be sure all equipment being transported by the inspector or service technician is properly secured in the vehicle.

- $\quad$ Practice defensive driving when traveling between sites.

h. field evaluation data;

i. calculations; 
j. numerical checks on calculation;

k. sealing/audit trail information; and

l. additional information such as device condition and other comments.

\subsubsection{Review Results}

\section{a. Test Data}

The test data are to be entered in the appropriate spaces on the report form during and immediately following the test.

b. Reporting Error

To report the error of the meter under test, the moisture value of the grain standard is subtracted from the average of three readings of the meter that is being tested

Error $=$ Average meter reading - Grain Standard Moisture Value

c. Explain Results to Device Owner

Explain the results to the device owner including any corrective action needed and the disposition of the device 
Part 2: Field Inspection and Evaluation

This page intentionally left blank 


\section{APPENDIX A. Grain Moisture Meter Sample Test Report Form}

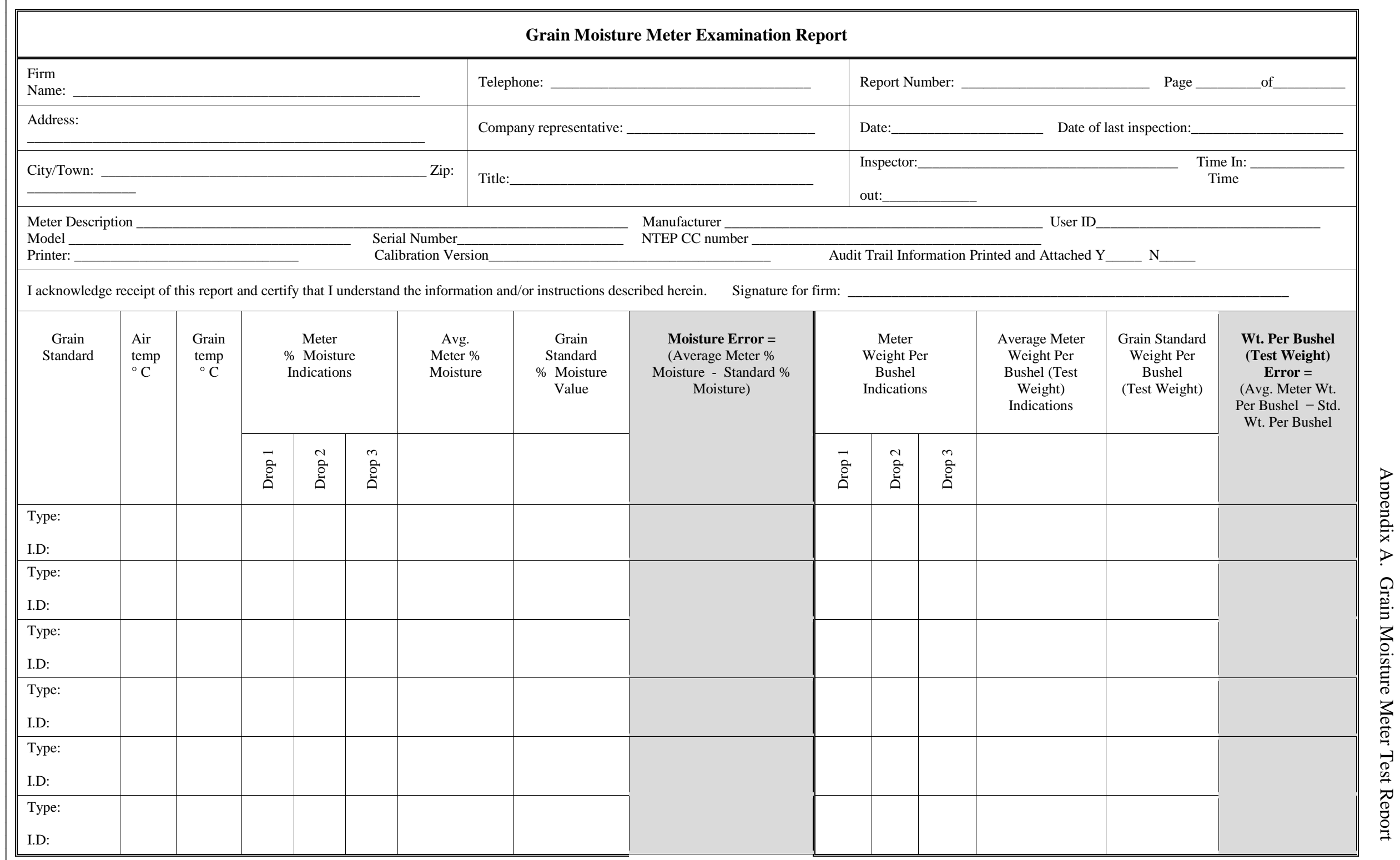




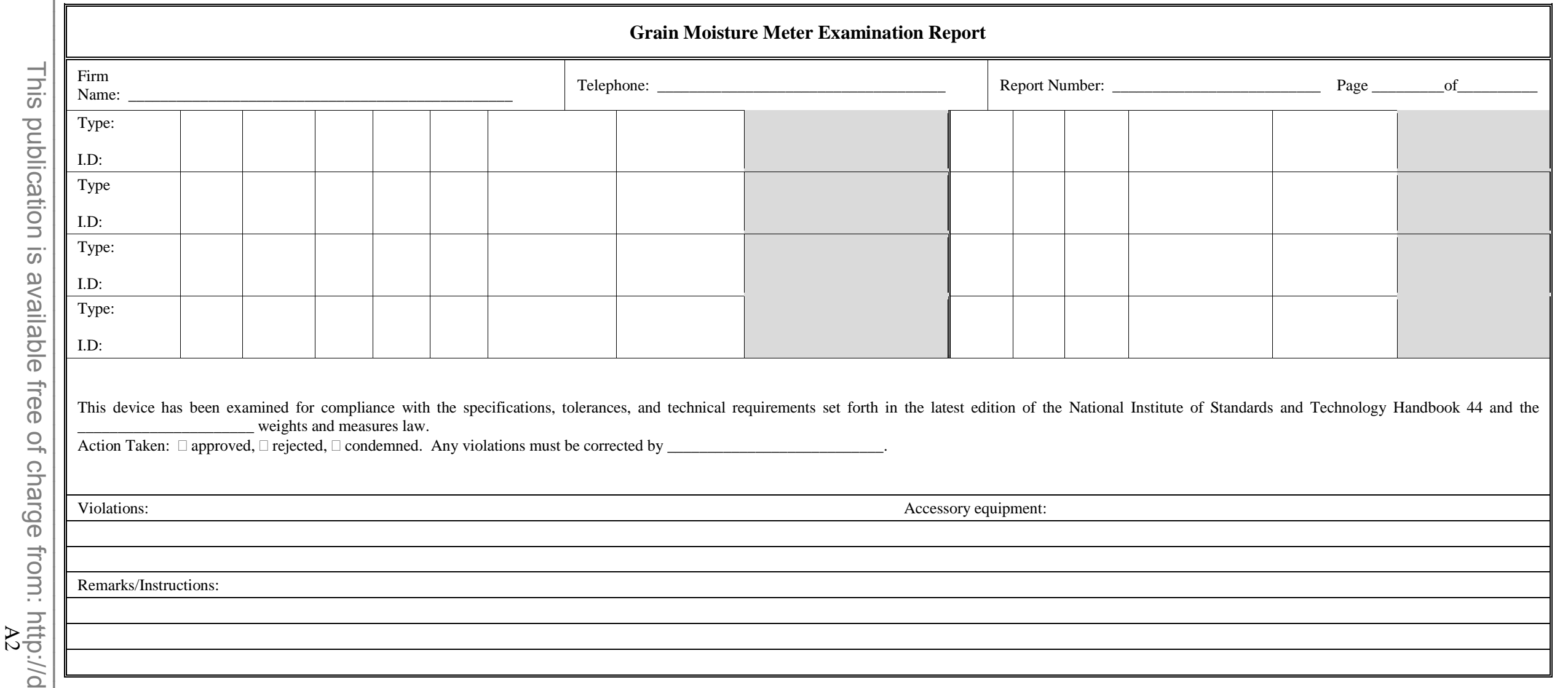




\section{Appendix B. Grain Moisture Air-Oven Reference Methods in the United States ${ }^{1}$}

Byline: G. Diane Lee

Grain moisture air-oven reference methods are used by many stakeholders in the United States and these reference methods play an important role in measurement accuracy and uniformity of commercial grain moisture meter measurements in the country. This article will provide a basic description of the air-oven reference methods and their use; discuss the importance of grain moisture measurements in legal-for-trade applications; identify the key users of the air-oven reference methods for commercial use; review the origins of these air-oven reference methods; and outline the specific air-oven reference methods used for the major U.S. grains.

\section{What are the grain moisture air-oven reference methods in the United States and how are they used?}

The grain moisture air-oven reference methods are procedures used to determine the percent moisture content in grain. Basically, a small sample of grain (ground or unground) that represents a larger sample set of that grain is placed in a small metal dish and the weight of the sample is recorded. The sample is then placed in an oven at a specific temperature and heated for a specific amount of time. The sample is removed from the oven and cooled in a container that prevents loss or gain of moisture during the cooling process. Then the sample is reweighed. The loss in the sample mass is calculated as the percent moisture content of the grain.

Commercial grain moisture meters are devices that provide a rapid prediction of moisture in grain and are used to test the moisture of grains that are bought and sold in the United States. Calibrations for commercial grain moisture meters are developed by comparing the grain moisture meter reading to grain moisture air-oven reference values. Also, airoven reference methods determine the reference moisture values of grain samples that verify the accuracy and operation of commercial grain moisture meters.

\section{Why are grain moisture measurements important in commercial (legal-for-trade) applications?}

Moisture is a critical commercial measurement in grain because "discounts" to the price per bushel of grain are made at the time of sale, based on the moisture content of the grain. "Discounts" are reductions to the price per bushel of grain. Two examples of discounts are drying and shrinkage discounts. A grain buyer must dry grain that is too high in moisture to prevent molding during storage. The cost associated with drying the grain or a "drying discount" is determined based on the grain moisture measurement at the time of sale. This discount reduces the amount of money the seller receives for the grain. For example, a buyer may be purchasing corn from a seller at $\$ 4.00$ per bushel of corn at a target or desired $15 \%$ moisture content. If the seller's corn is higher in moisture content at the time of sale than is targeted or desired, the buyer will reduce the unit price per bushel he will give the seller for the grain. Grains that are too high in moisture may be placed into storage with aeration causing shrinkage. The cost associated with shrinkage or a "shrinkage discount" is also based on the moisture of the grain at the time of sale. Errors in the moisture measurements may result in large losses to either the seller or buyer of grain. See article number C-006, March 2007 "The Economic Impact of Errors in Moisture Measurements, Part 2, Grain Moisture Meter Series," located at: www.nist.gov/pml/wmd/pubs/archives-grain-moisture.cfm, for additional information on discounts.

\section{Who uses air-oven reference methods?}

Stakeholders in the United States that use air-oven reference methods as the basis for commercial measurements of moisture in grain include:

${ }^{1}$ Source: Weights and Measures Connection, Volume 3, Issue 6, November 19, 2012. 
Appendix B. Grain Moisture Air-Oven Reference Methods in the United States

The U.S. Department of Agriculture, Grain Inspection, Packers, and Stockyards Administration (USDA, GIPSA);

- The National Type Evaluation Program (NTEP) Laboratory for Grain Moisture Meters;

- Grain Moisture Meter (GMM) Manufacturers; and

- State Weights and Measures and other state officials.

These organizations work together to ensure equity in the commercial grain market as illustrated in Figure 1 . The System of Commercial Grain Moisture Measurements in the United States, and Figure 2., The Movement of Grain in The United States and Inspection Points.

The USDA, GIPSA uses air-oven reference methods to develop the calibrations for the official grain moisture meter(s). These official grain moisture meters are used to measure the moisture of grains at export locations and upon request at interior grain facilities in the United States.

The National Type Evaluation Program (NTEP) Laboratory at the USDA, GIPSA uses these air-oven reference methods when analyzing a national grain sample set and providing manufacturers with data to develop the calibrations for all grain moisture meters used in commercial service in the United States. These reference methods are also used to evaluate commercial (i.e., legal for trade) grain moisture meters in the NTEP laboratory to determine if prototypes of the device meet the requirements of the National Institute of Standards and Technology (NIST) Handbook 44 Specifications, Tolerances, and Other Technical Requirements for Weighing and Measuring Devices, prior to being used commercially in the United States. See Figure 1., the system of commercial grain moisture measurements in the United States.

State Weights and Measures Officials and other State Officials use these reference methods to determine the moisture in grain samples that are used to test commercial grain moisture meters. Typically, the grain moisture meters tested by State Weights and Measures or other state officials are at local elevators that purchase grain from farmers in their jurisdictions. See Figure 1., the system of commercial grain moisture measurements in the United States and Figure 2., the movement of grain in the United States and inspection points.

Manufacturers of grain moisture meters use these reference air-oven moisture methods when developing the calibrations for grain moisture meters that they sell for use in legal-for-trade applications. (See Figure 1. The system of commercial grain moisture measurements in the United States.) 


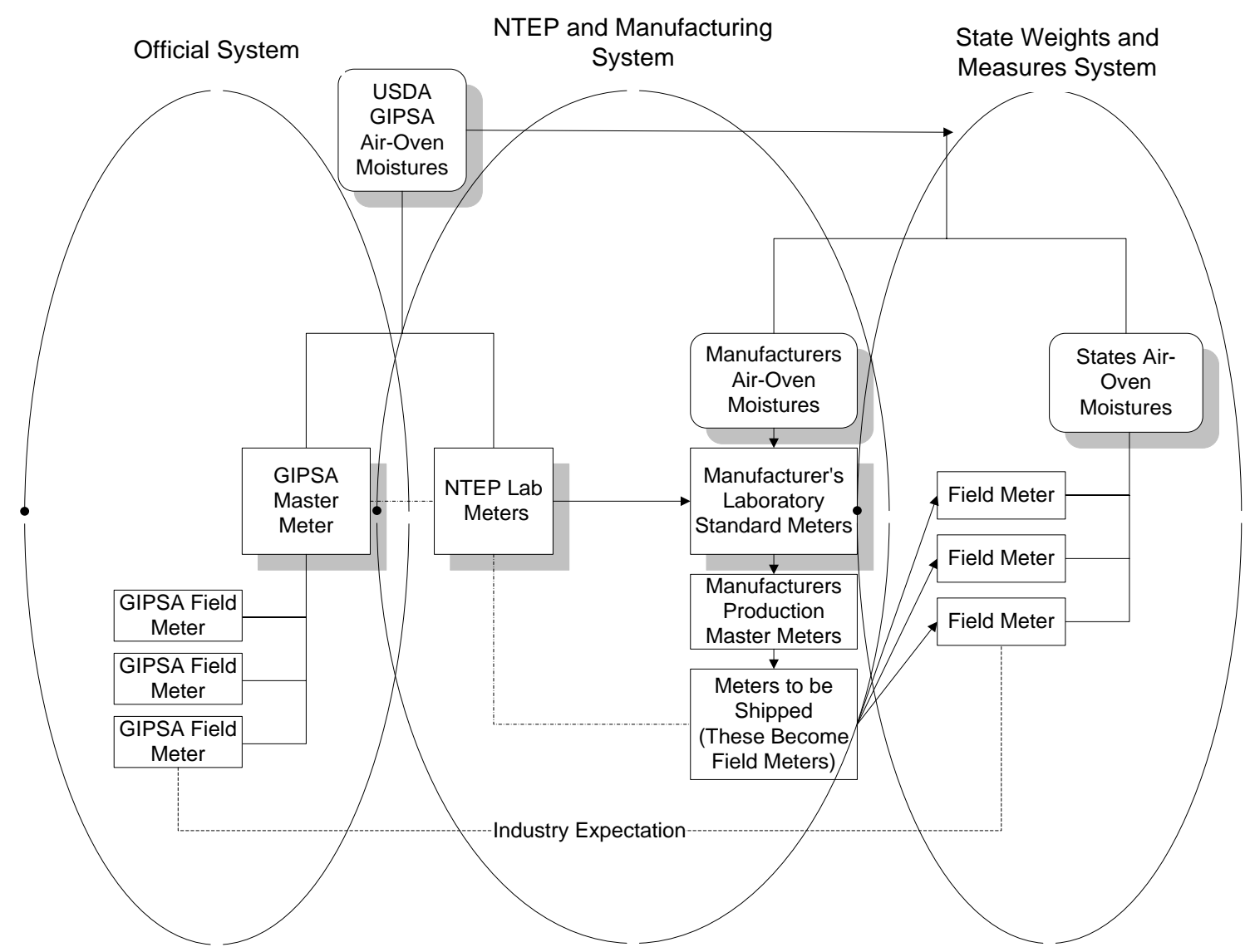

Figure 1. The System of Commercial Grain Moisture Measurements in the United States.

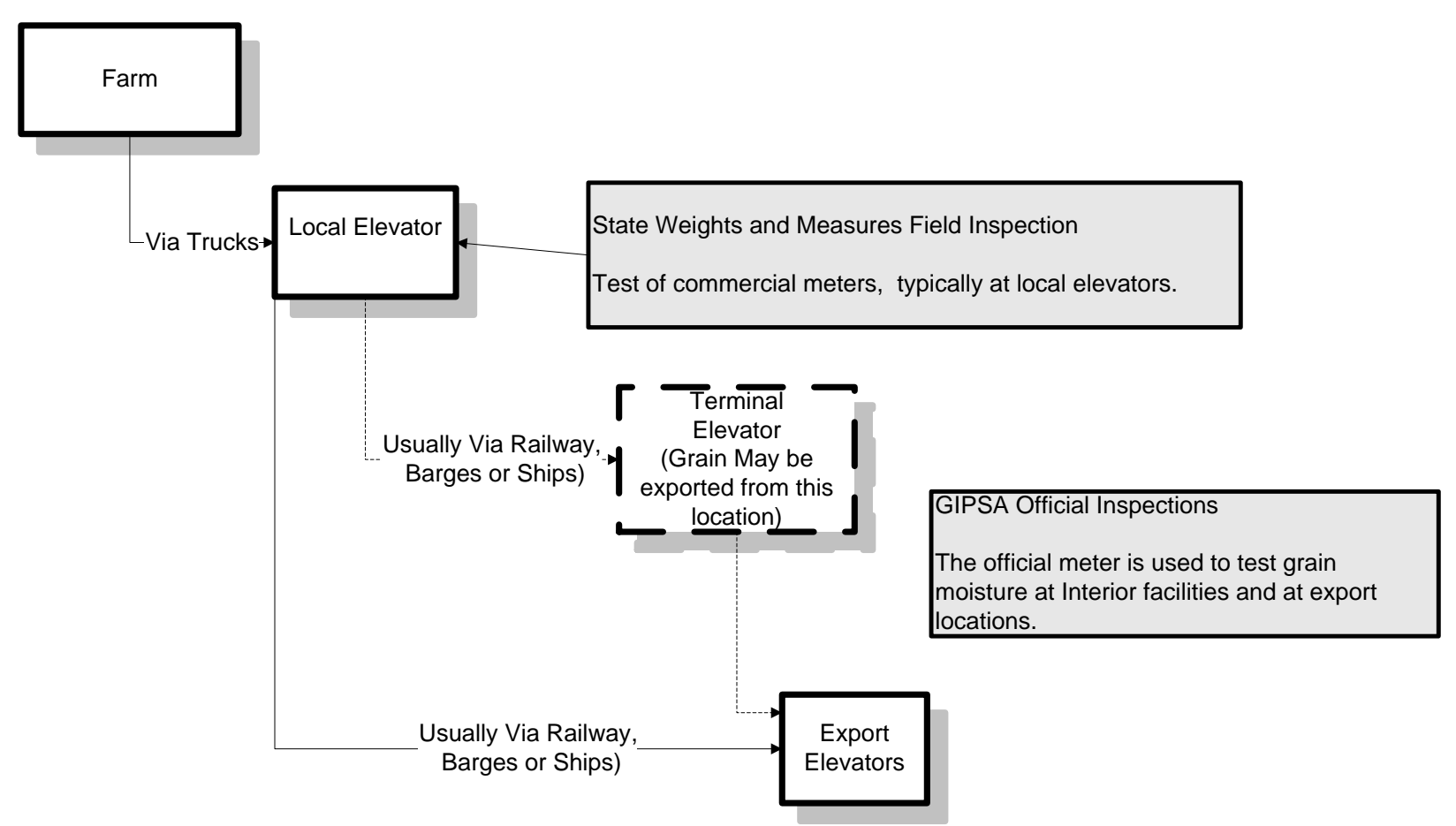

Figure 2. The Movement of Grain in the United States and Inspection Points. 


\section{History of Air-oven Reference Methods in the United States}

The most widely recognized reference methods for determining moisture content in grain are based on drying known weights of grain in various types of ovens and calculating moisture content from the weight lost in the drying operation. $^{2}$ The USDA, GIPSA, identifies the "air-oven methods" as its official reference methods for determining moisture in grain and oil seeds. According to the history of changes to USDA, GIPSA grain standards, these air-oven reference methods have been in use since July 1, 1935. The USDA, GIPSA air-oven reference methods were accepted by the American Association of Cereal Chemists (AACC, currently known as AACC International), Method 44-15A. Although oven methods are subject to error due to the loss of substances other than water during the drying process, Hart and Neustadt adapted the use of Karl Fisher (KF) Titration in 1957 to test the accuracy of the USDA air-oven moisture methods. ${ }^{i}$ The USDA air-oven methods were designed to give results which agree with those obtained by KF Titration. KF Titration provides moisture values by extracting water from grain with the use of a solvent, such as methanol, and is more specific for grain moisture. Historical records have noted that KF Titration required more time for testing than was practical and, due to the test process at that time, there were repeatability issues from operator to operator due to portions of the test that were not automated. Frank E. Jones and Carroll S. Brickenkamp, National Bureau of Standards (NBS, now known as the National Institute of Standards and Technology), National Engineering Laboratory, noted that techniques were developed to automate KF Titration to address some of the earlier disadvantages of this method. Jones and Brickenkamp also noted that, although the KF Titration is more specific for moisture, additional tests are needed to determine if other substances react with the solvent used to extract water.3 The air-oven reference methods remains the reference methods for moisture in the United States; this is likely because these methods have been compared to KF Titration and/or other more definitive tests and have proven to provide very repeatable measurements.

\section{Air-oven Reference Methods for Major U.S. Grains}

There are currently eight air-oven moisture reference methods used to determine moisture in the major U.S. grains and these methods are recognized internationally. These reference methods vary per grain type, moisture, and commodity and are maintained at the USDA, GIPSA in the Technology and Science Division's Laboratory Work Instructions. These work instructions include specific procedures, guidance on test sample size, equipment and material, and acceptance criteria needed for each test. Because these air-oven reference methods vary per grain type, the following tables are provided to summarize the different air-oven reference methods used in the United States.

AO_1

Single-Stage Air-Oven Reference Method for Moisture in Grains, Oilseeds, and Commodities: is the difference in weight after drying a ground sample of grain for one hour at $130{ }^{\circ} \mathrm{C} \pm 1{ }^{\circ} \mathrm{C}$ (drying time is two hours for soybean meal). The following grains and commodities are tested using this method:

\begin{tabular}{|c|c|c||}
\hline \multicolumn{2}{|c|}{ Grains and Oilseeds } & Commodities \\
\hline Description & $\begin{array}{c}\text { Moisture } \\
\text { Restriction }\end{array}$ & Description \\
\hline Barley & $\leq 16 \%$ & Barley - submitted \\
\hline Lentils & $\leq 16 \%$ & Bulgur \\
\hline Oats & $\leq 16 \%$ & Corn Soy Blend \\
\hline Pea & $\leq 16 \%$ & Corn Soya Flour \\
\hline Rice, brown & $\leq 16 \%$ & Corn Soy Milk \\
\hline Rice, milled & $\leq 16 \%$ & Corn - submitted \\
\hline Rice, rough & $\leq 13 \%$ & Corn Meal \\
\hline Rye & $\leq 16 \%$ & Dessert Powder \\
\hline
\end{tabular}

\footnotetext{
${ }^{2}$ Storage of Cereal Grains and Their Products, Chapter 1: Moisture-Its Significance, Beahavior, and Measurement, W. Harward Hung and S.W. Pixton.

${ }^{3}$ Journal of AOAC, Volume 64, Number 6, 1981, Frank E. Jones and Carroll S. Brickenkamp.
} 
AO_1

Single-Stage Air-Oven Reference Method for Moisture in Grains, Oilseeds, and Commodities: is the difference in weight after drying a ground sample of grain for one hour at $130{ }^{\circ} \mathrm{C} \pm 1{ }^{\circ} \mathrm{C}$ (drying time is two hours for soybean meal). The following grains and commodities are tested using this method:

\begin{tabular}{|c|c|c|}
\hline \multicolumn{2}{|l|}{ Grains and Oilseeds } & \multirow{2}{*}{$\begin{array}{c}\text { Commodities } \\
\text { Description } \\
\end{array}$} \\
\hline Description & $\begin{array}{l}\text { Moisture } \\
\text { Restriction }\end{array}$ & \\
\hline Sorghum & $\leq 16 \%$ & Egg Noodles \\
\hline Soybeans & $\leq 10 \%$ & Hominy Grits \\
\hline Sunflower ground 50/50 with celite & $\begin{array}{c}\text { Non (for } \\
\text { moisture } \\
\text { correction } \\
\text { of crude oil } \\
\text { results }\end{array}$ & Icing Mix Powder \\
\hline Triticale & $\leq 16 \%$ & Lasagna \\
\hline Wheat & $\leq 16 \%$ & Macaroni \\
\hline & & Macaroni and Cheese \\
\hline & & Rotini \\
\hline & & Rolled Wheat \\
\hline & & Sorghum Grits \\
\hline & & Soybean Meal \\
\hline & & Spaghetti \\
\hline & & Wheat Flour \\
\hline & & Wheat Soy Blend \\
\hline & & Wheat Soy Milk \\
\hline & & Wheat - submitted \\
\hline
\end{tabular}




\begin{tabular}{|c|c|}
\hline AO_2 \\
Two-Stage Air-Oven Reference Method for Moisture in Grains and Oilseeds is the difference \\
in weight after air-drying a unground sample of grain until its moisture content is \\
$\leq 16 \%(\leq 10 \%$ for soybeans and $\leq 13 \%$ for rough rice), then drying the ground, air-dried \\
sample for one hour at $130{ }^{\circ} \mathrm{C} \pm 1{ }^{\circ} \mathrm{C}$ (two hours for soybean meal). The following grains are \\
tested using this method: \\
\hline \multicolumn{2}{|c|}{ Grains and Oilseeds } \\
\hline Description & $\begin{array}{c}\text { Moisture } \\
\text { Restriction }\end{array}$ \\
\hline Barley & $>16 \%$ \\
\hline Lentils & $>16 \%$ \\
\hline Oats & $>16 \%$ \\
\hline Peas & $>16 \%$ \\
\hline Rice, brown & $>16 \%$ \\
\hline Rice, milled & $>16 \%$ \\
\hline Rice, Rough & $>13 \%$ \\
\hline Rye & $>16 \%$ \\
\hline Sorghum & $>16 \%$ \\
\hline Soybeans & $>10 \%$ \\
\hline Triticale & $>16 \%$ \\
\hline wheat & $>16 \%$ \\
\hline AACC Method 44-15A;, ASTM; NIST; Kenyon, A.S., Black, J.C., \& Layloff, T.P. \\
\hline Cited References: \\
(1995); J. Assoc. Off. Anal. Chem. 78, 1109-1111.
\end{tabular}

\section{AO_3}

Air-Oven Reference Method for Moisture in Corn and Beans is the difference in weight after drying an unground sample of grain for 72 hours at $103^{\circ} \mathrm{C} \pm 1{ }^{\circ} \mathrm{C}$. The following grains are tested using this method:

\begin{tabular}{|c|c|}
\hline \multicolumn{2}{|c|}{ Grains } \\
\hline Description & Moisture \\
\hline Corn & Any \\
\hline Beans & Any \\
\hline
\end{tabular}

Cited References: AACC Method 44-15A; ASTM; NIST; Kenyon, A.S., Black, J.C., \& Layloff, T.P. (1995); J. Assoc. Off. Anal. Chem. 78, 1109-1111. 


\begin{tabular}{|c|c|}
\hline $\begin{array}{l}\text { AO_4 } \\
\text { Air-Oven Reference Method for } \\
\text { difference in weight after drying } \\
\pm 1{ }^{\circ} \mathrm{C} \text { (two hours for soybean } n \\
\text { the } 1^{\text {st }} \text { and } 2^{\text {nd }} \text { weight after each } \\
\text { an additional hour. The followin }\end{array}$ & $\begin{array}{l}\text { and Rapeseed is the } \\
\text { r one hour at } 103^{\circ} \mathrm{C} \\
\text { e difference between } \\
\text { e sample is dried for } \\
\text { thod: }\end{array}$ \\
\hline & \\
\hline Description & Moisture \\
\hline Mustard & Any \\
\hline Canola & Any \\
\hline Rapeseed & Any \\
\hline
\end{tabular}

AO_5

Air-Oven Reference Method for Moisture in Flaxseed is the difference in weight after drying an unground sample of seed for four hours at $103^{\circ} \mathrm{C} \pm 1{ }^{\circ} \mathrm{C}$. The following grains are tested using this method:

\begin{tabular}{|c|c|}
\hline \multicolumn{2}{|c|}{ Grain } \\
\hline \multicolumn{1}{|c|}{ Description } & \multicolumn{1}{|c|}{ Moisture } \\
\hline \multicolumn{1}{|c|}{ Flaxseed } & Any \\
\hline $\begin{array}{l}\text { Cited References: AACC Method 44-15A; ASAE Method S352.2; ASTM; NIST; } \\
\text { Kenyon, A.S., Black, J.C., \& Layloff, T.P. (1995); J. Assoc. Off. Anal. Chem. 78, } \\
1109-1111 .\end{array}$ \\
\hline
\end{tabular}

\section{AO_6}

Air-Oven Reference Method for Moisture in Safflower seeds is the difference in weight after drying an unground sample of seed for one hour at $130^{\circ} \mathrm{C} \pm 1{ }^{\circ} \mathrm{C}$. The following grain is tested using this method:

\begin{tabular}{|c|c|}
\hline \multicolumn{2}{|c|}{ Grain } \\
\hline Description & Moisture \\
\hline Safflower seeds & Any \\
\hline \multicolumn{2}{|c|}{$\begin{array}{l}\text { Cited References: ASAE Method S352.2; ASTM; NIST; Kenyon, A.S., Black, } \\
\text { J.C., \& Layloff, T.P. (1995); J. Assoc. Off. Anal. Chem. 78, 1109-1111. }\end{array}$} \\
\hline
\end{tabular}

AO_7

Air-Oven Reference Method for Moisture in Sunflower seeds is the difference in weight after drying an unground sample of seed for three hours at $130{ }^{\circ} \mathrm{C} \pm 1{ }^{\circ} \mathrm{C}$. The following grain is tested using this method:

\begin{tabular}{|c|c|}
\hline \multicolumn{2}{|c|}{ Grain } \\
\hline \multicolumn{1}{|c|}{ Description } & Moisture \\
\hline \hline \multicolumn{1}{|c|}{ Sunflower seeds } & Any \\
\hline $\begin{array}{l}\text { Cited References: AOAC Method Ac 2-41; AOAC Method Ai 2-75; ASTM; NIST; } \\
\text { Kenyon, A.S., Black, J.C., \& Layloff, T.P. (1995); J. Assoc. Off. Anal. Chem. 78, 1109- } \\
1111 .\end{array}$ \\
\hline
\end{tabular}




\begin{tabular}{|c|c|}
\hline \multicolumn{2}{|c|}{$\begin{array}{l}\text { AO_8 } \\
\text { Air-Oven Reference Method for Moisture in Corn Gluten Feed is the difference in weight } \\
\text { after drying the ground sample for four hours at } 103^{\circ} \mathrm{C} \pm 1{ }^{\circ} \mathrm{C} \text {. The following sample is } \\
\text { tested using this method: }\end{array}$} \\
\hline \multicolumn{2}{|c|}{ Grain } \\
\hline Description & Moisture \\
\hline Corn Gluten Feed & Any \\
\hline \multicolumn{2}{|c|}{$\begin{array}{l}\text { Cited References: Method of the Corn Refiners Association; ASTM; NIST; Kenyon, } \\
\text { A.S., Black, J.C., \& Layloff, T.P. (1995); J. Assoc. Off. Anal. Chem. 78, 1109-1111. }\end{array}$} \\
\hline
\end{tabular}

\begin{tabular}{||ll||}
\hline $\begin{array}{l}\text { AO_10 through AO_15 are reference methods for other commodities and processes for } \\
\text { laboratory check samples and equipment maintenance: }\end{array}$ \\
\hline \hline AO_10 & $100^{\circ} \mathrm{C}$ Vacuum Oven Reference Method for moisture in Commodity Samples \\
\hline AO_11 & Processing the Air-Oven Laboratory Wheat Check Sample \\
\hline AO_12 & Processing the Air-Oven Laboratory Corn Check Sample \\
\hline AO_13 & Air-Oven Uniformity Check \\
\hline AO_14 & Calibrating the Thermometers Used in the Air-Oven Laboratory \\
\hline AO_15 & Moisture Dish Maintenance and Tare Weight Check Schedule \\
\hline
\end{tabular}

Many studies of air-oven reference methods have been conducted over the years since the first use of these reference methods. These studies resulted in changes to the air-oven reference methods that improved the accuracy of grain moisture meter measurements. The air-oven reference methods are well established in the United States. Stakeholders use these reference methods to develop the calibrations for all commercial grain moisture meters and to test these devices to provide uniformity in the market place.

NIST, OWM greatly appreciates the review and comments of Dr. Richard Pierce, USDA, GIPSA during the development of this article.

For additional information concerning this article, please contact Diane Lee by e-mail at diane.lee@nist.gov or the Office of Weights and Measures at (301) 975-4004, e-mail at owm@nist.gov. 


\section{Appendix C. Determining Reference Test Weight per Bushel Value of Grains ${ }^{1}$}

By G. Diane Lee

"Test weight per bushel" is a measurement of the weight of a volume of grain required to fill level a Winchester bushel measure of 2150.42 cubic inches (equivalent to 32 quarts) in capacity ${ }^{2}$. Test weight per bushel is one of the measurements used by the U.S. Department of Agriculture (USDA), Grain Inspection Packers and Stockyards Administration (GIPSA) in grain grading. For example, USDA No. 1 hard red spring wheat has a minimum limit for test weight per bushel of 58.0 pounds per bushel. In the market place, test weight per bushel is a commercial measurement because it affects the market value of grain. When a farmer sells grain, the grain price may be “discounted.” If "discounted” for test weight, the farmer receives less money for the grain if the test weight per bushel measurement is under a certain specified target weight per bushel, such as 58.0 pounds per bushel. Many grain moisture meters, currently in commercial use, that are covered by a National Type Evaluation Program (NTEP) Certificate of Conformance, provide grain test weight per bushel measurements that are used to assess the amount of money a farmer will receive for grain. As such, the "test weight per bushel" measurement must be verified for accuracy. The process used to verify the accuracy of a meter's test weight per bushel measurement begins in the laboratory. Both the NTEP laboratory and state weights and measures laboratories use a reference test weight per bushel measurement procedure, and specific equipment to determine the reference test weight per bushel values of various grains. Once a reference test weight per bushel value is determined for the grains, the grains are used to verify the accuracy of the test weight per bushel feature on meters. Both the NTEP laboratory and State Weights and Measures field inspectors verify the accuracy of the weight per bushel measurement of meters by comparing the results of the weight per bushel measurement on the meter to the reference "test weight per bushel" value of the grain samples that are placed in the meter for measurement. This article addresses the laboratory equipment, equipment maintenance, and reference procedures for test weight per bushel because of its importance in determining the accuracy of the test weight per bushel measurement of meters.

\section{Equipment}

To determine reference test weight per bushel measurements of grain, use test weight per bushel equipment approved by USDA, GIPSA. The USDA, GIPSA Equipment Handbook includes two lists of GIPSA approved equipment: active and inactive. The active equipment list includes GIPSA approved equipment that is commercially available. The inactive equipment list contains GIPSA approved equipment no longer manufactured or widely marketed, but is still approved for use. The equipment used to determine reference test weight per bushel values for grain are:

- a quart kettle,

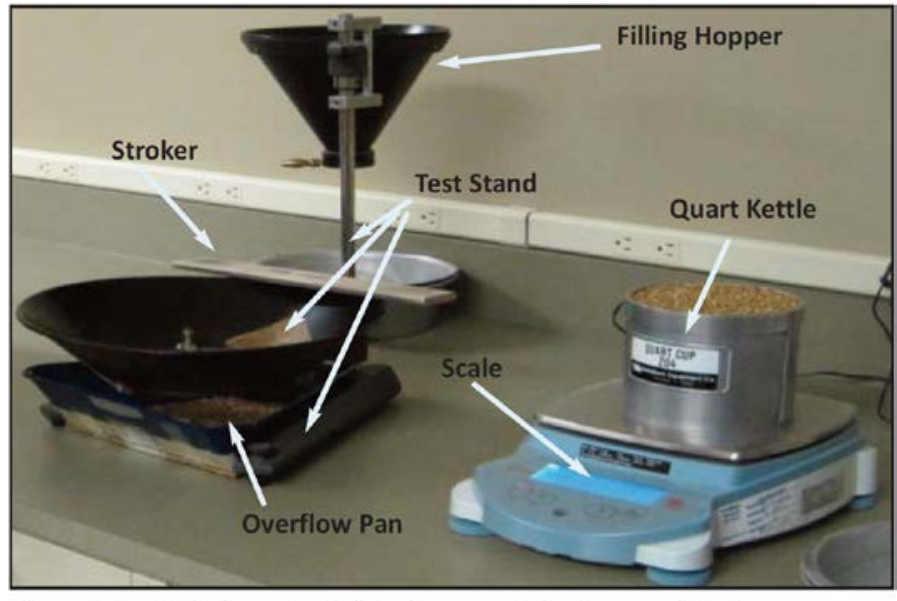

Figure 1. Test Weight per Bushel Equipment - Active Approved Equipment

${ }^{1}$ Source: Weights and Measures Connection, Volume 4, Issue 6, September 26, 2013

${ }^{2}$ Circular No. 921 U.S. Department of Agriculture, June 1953 
- a scale specifically designed to measure test weight per bushel,

- a filling hopper,

- $\quad$ an over flow pan, and

- a stroker.

Figure 1. Test Weight per Bushel Equipment - Active Approved Equipment includes test weight per bushel equipment from GIPSA's active approved equipment list and currently in use at the USDA, GIPSA in Kansas City, Missouri.

\section{Equipment Maintenance}

The test weight per bushel equipment must be checked and adjusted prior to initial use; and periodically, thereafter, as needed. A maintenance schedule of the checks and adjustments made to the equipment must be documented. The specifications and maintenance for test weight per bushel equipment are included in GIPSA's Equipment Handbook, which can be downloaded from the USDA, GIPSA Website at:

http://www.gipsa.usda.gov/fgis/handbook/equip_inspec.aspx

\section{Procedure for Determining the Reference Test Weight per Bushel Value of Grains}

In general, the procedure used to determine the reference test weight per bushel of grain is to weigh one dry quart of the grain on a suitable scale that is designed to multiply the weight by 32, since there are exactly 32 quarts to a dry bushel. These specially designed scales provide a direct reading of test weight per bushel. Since these scales indicate 32 times the weight of the content in the dry quart, it is very important to follow procedures for determining the reference test weight per bushel values of grain.

The following is a step-by-step procedure to determine the reference test weight per bushel values of grain samples that are used to test meters or other equipment used to provide test weight per bushel measurements to customers in the marketplace.

1. Before starting the procedure, ensure that the equipment is positioned

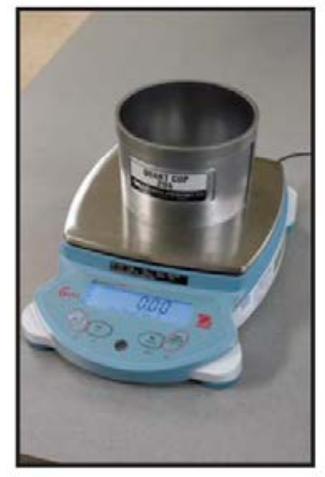

Figure 2. Zero weight of the empty quart kettle. correctly by placing a level on top of the quart kettle to ensure that it is in a level condition on the test stand and position the filling hopper two inches above the top of the quart kettle. Procedures for measuring this distance are included in Chapter 5 of the USDA GIPSA Equipment Handbook.

2. Place the empty quart kettle on the scale; then zero the scale (Figure 2. Zerio Weight of the Empty Quart Kettle).

3. Close the bottom of the fill hopper; place about 11/8 quart of grain in the filling hopper, and place the quart kettle on the test stand.

4. Position the fill hopper over the quart kettle by swiveling the fill hopper and fill the kettle from the hopper (Figure 3. Filling the Quart Kettle from the Filling Hopper). Do not move the kettle while it is being filled.

5. Once the quart kettle is full, move the fill hopper away from the quart kettle being careful not to move the kettle.

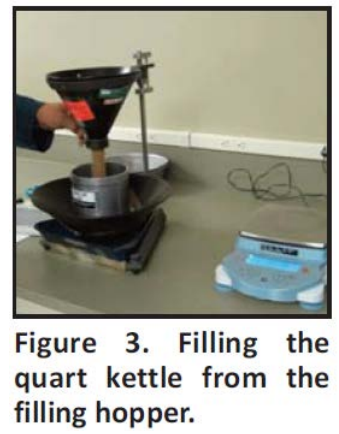




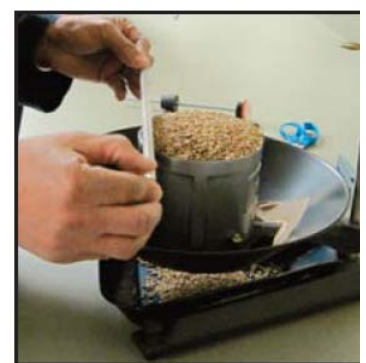

Figure 3a. Remove exces grain.

6. Hold the stroker on each end with your fingers so that the sides are in a vertical position and place it lightly on the edge of the kettle without moving the kettle (Figure 3a. Remove Excess Grain).

7. Stroke the excess grain from the top of the quart kettle in a zigzag motion with three full strokes. Each stroke should cover $1 \frac{1}{3}$ of the top of the kettle (Figure 3b. Stroke Pattern: Start with the Stroker at the Edige of the Quart Kettle and Follow a ZigZag Pattern).

Important Note: Scales used to measure test weight per bushel are specially designed to provide an indication that is 32 times the weight of the grain in the quart kettle. So, if the quart kettle contains 1 pound, then the scale will show a weight per bushel indication of 32 pounds per bushel (1 to 32 ratio). It is extremely important to follow the procedure for step 6 , stroking excess grain from the quart kettle because too much or too little grain removed, will impact the measurement by a multiple of 32 (e.g., if 1 ounce of grain is removed that should have been part of the measurement there will be a 2.0 pounds per bushel error in the test weight per bushel measurement).

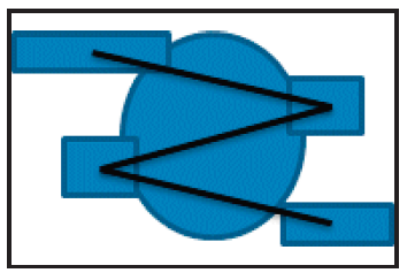

Figure 3b. Stroke pattern: Start with the stroker at the edge of the quart kettle and follow a zigzag pattern.

\section{Example of calculation:}

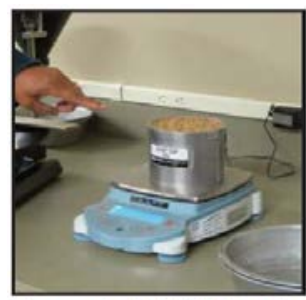

Figure 4. Weighing the quart kettle and grain.

$1 \mathrm{lb}=16 \mathrm{oz}$

$1 \mathrm{oz} / 16 \mathrm{oz}=0.0625 \mathrm{lb}$,

so, $0.0625 \mathrm{lb} \times 32=2.0 \mathrm{lb}$

8. Carefully remove the quart kettle from the stand and weigh the kettle and grain on the scale and record your results. (See Figure 4. Weighing the Quart Kettle and Grain)

In accordance with the National Institute of Standards and Technology (NIST) Handbook 44, Specifications, Tolerances, and Other Technical Requirements for Weighing and Measuring Devices, Section 5.56.(a) Grain Moisture Meters, paragraph N.1.1. Air-Oven Reference Method Transfer Standards, repeat steps 1 through 8, 10 times and average the results for each grain type. The test weight per bushel value assigned to the grain samples is the average of 10 measurements. When assigning this value, it must be noted that when a standard is used without correction, the combined error and uncertainty in your measurement must be less than one-third of the applicable tolerances, in accordance with NIST Handbook 44, Appendix A. Fundamental Considerations, Section 3.2. "Tolerances for Standards."

The consistent use of proper techniques and proper equipment is key to successfully determining the reference values for test weight per bushel.

Using the prescribed test procedures and correct equipment, as provided in this article along with maintaining your equipment in accordance with the USDA, GIPSA Equipment Handbook will reduce the variability and error in your reference test weight per bushel measurements made in the laboratory. Practice removing the excess grain from the quart kettle will result in better measurement repeatability. Additionally, grain samples with accurate weight per bushel values will help to ensure proper testing of meter weight per bushel measurements.

\section{Resources for Test Weight per Bushel Reference Measurements}

- USDA, GIPSA Equipment Handbook at: http://www.gipsa.usda.gov/Publications/fgis/handbooks/equip_insphb.html.

- Circular No. 921 "The Test Weight per Bushel of Grain: Methods of Use and Calibration of the Apparatus,” June 1953, United States Department of Agriculture. 
Appendix C. Reference Test Weight Value of per Bushel Value of Grains

For additional information concerning this article you may contact Diane Lee of the NIST, Office of Weights and Measures (OWM) by e-mail at diane.lee@nist.gov, or contact the office at owm@nist.gov, phone (301) 975-3998.

Note: It is policy of the National Institute of Standards and Technology to use metric units of measurement in all of its publications. However, in this newsletter the references to inch-pound units are used as they are commonly used in industry practice and in source documentation. 
INSIDE BACK COVER - BLANK 


\section{BACK COVER}

